Sonja Lehmann

\title{
Transnational Identities in Michael Ondaatje's Fiction
}

\section{Introduction: Transnational Identities in Michael Ondaatje's Fiction}

Ever since his 1982 fictionalized memoir Running in the Family, Michael Ondaatje's fiction has been characterized by a concern for the lives of migrants. More precisely, it predominantly focuses on the questions of identity that result from the characters' migrations. Thus, the narrator of Running in the Family travels to Sri Lanka trying to come to terms with how his long neglected Sri Lankan heritage influences his identity. Anil, the protagonist of Anil's Ghost, faces similar questions and likewise returns to her country of origin to reconnect with her past in wartorn Sri Lanka. In the Skin of a Lion's hero, Patrick Lewis, undertakes a more metaphorical kind of migration by becoming part of Toronto's Macedonian diaspora in the first half of the $20^{\text {th }}$ century, which is contrasted with the Macedonian Nicholas Temelcoff's immigration to Canada. Both of them accordingly have to adjust to their new environment and adjust their self-understanding in the process. The English Patient's eponymous protagonist calls himself an "international bastard" (The English Patient 188) and in a somewhat questionable move extends this label to the Indian sapper, Kip, who like the patient is part of a multinational commu- 
nity in Italy at the end of World War II, but has a quite different understanding of identity and belonging. Finally, Anna, the central character of Divisadero, sees her life as a network that surpasses the boundaries between nations, characters, fiction and reality, and even time. As a result "[e]verything is collage" (Divisadero 16), even Anna's identity, as she imagines herself to belong to and identifies with all the different story lines in the novel.

While all these texts differ greatly in plot and setting they nevertheless depict a set of characters whose identities are equally influenced by multiple affiliations and affinities that cut across national and cultural boundaries. Even though Ondaatje's fiction stresses that such identities are not always easy to live with, especially in conditions where one's environment does not welcome them, there is still almost always some sense of reconciliation in the texts which makes simultaneously taking part in several cultures and nations seem possible. The sense of loss and displacement that all characters at one point feel as a result of their migrations mostly gives way to at least a little hope for a more positive and empowering sense of belonging to several places.

This sets Ondaatje's fiction apart from other forms of postcolonial migrant writing which often emphasizes the displacement and in-betweenness of migrants. Accordingly, Pico Iyer states, "Ondaatje is harder to place than many of his fellow exile writers, and there is always a sense in his books that he is trying to create a new kind of mongrel fiction that leaves old categories behind" ("Mongrel Fiction" no pag.). Iyer presents an interesting hypothesis here that I will attempt to answer with my thesis: whether Ondaatje's fiction is a new kind of migrant writing that requires a different theoretical approach compared to more traditional migrant literature.

The topic of transnational identities is ideal for this endeavour since transnational migration is a rather new phenomenon that is not well established in theories of postcolonial migrant writing yet. However, transnational theories appear very apt to describe the workings of Ondaatje's fiction since they emphasize simultaneity, the dissolution of boundaries and the importance of spaces in the formation of transnational identities. All these aspects can repeatedly be found in Ondaatje's writings as my brief introduction to the works to be analyzed in this study has already shown.

I will therefore at first summarize how identity is dealt with in postcolonial theory and compare this to sociological and anthropological studies on transnational migration in order to propose a theory on the formation of transnational identities and analyze Ondaatje's fiction in terms of this. This should not only prove useful for an analysis of the treatment of identities in Ondaatje's works but also point out how cultural globalization has affected the kind of literature that is produced in our times. 


\section{Migration, Belonging and Identity}

\subsection{Migrant Writing and Contemporary International Migration}

Migration is a recurrent topic in postcolonial literature. This is hardly surprising since many of the most prominent postcolonial authors are migrants themselves, such as Salman Rushdie, Ben Okri, Jamaica Kincaid, Michael Ondaatje and many others. However, migration is not only the matter of many literary works but it also a source for of theoretical reflections on the migrant condition. As John McLeod says, "[t]he experiences of migrancy and living in a diaspora have animated much recent postcolonial literature, criticism and theory" (207). Especially its effects on migrants' identities are explored extensively. These identities are generally seen as "doubled, or hybrid, or unstable" (Barry 196) and the protagonists of migrant literature are often portrayed as being unsure of who they are, where they belong and how to reconcile their location between several cultures and countries. This perception of identities is closely connected with the notions of place, displacement and exile in postcolonial theory. Bill Ashcroft, Gareth Griffiths and Helen Tiffin explain this in the following way:

A major feature of post-colonial literatures is the concern with place and displacement. It is here that the special post-colonial crisis of identity comes into being; the concern with the development or recovery of an effective identifying relationship between self and place. (Empire 8)

Their emphasis on the interrelationship of "place" and "self" is striking. It implies that in order to not suffer from a crisis of identity one has to somehow be connected to and identify with the place one inhabits. To be separated from this place - or to be otherwise alienated from it through the effects of colonization - consequently is not only a change of location but is also accompanied by a sense of displacement and a "crisis of identity". Displacement hence appears to be a necessary consequence of migration which is therefore also frequently referred to as a form of "exile", "from either a literal homeland or from a cultural and ethnic origin" (Ashcroft, Griffiths and Tiffin, "Exile" 92). To say where such migrants and diasporeans are at home is considered very difficult: "Where is the place of 'home' to be located for such people or such groups? In the place of birth (nateo), in the displaced cultural community into which the person is born, or the nation-state in which this diasporic community is located?" (Ashcroft, Griffiths and Tiffin, "Exile" 93; emphasis in original).

This sentiment is most famously expressed by Rushdie in his essay "Imaginary Homelands" in which he refers to migrant writers as "exiles or emigrants or expatriates, [who] are haunted by some sense of loss, some urge to reclaim, to look back" which leads to "physical alienation" and "profound uncertainties" (10). He emphasizes that this alienation does not only apply to the country of immigration 
but also to the country left behind which turns into an "imaginary homeland" that has little to do with the reality anymore (10). Rushdie's migrant seems perpetually stuck in-between these two while not belonging to either one. The migrant relies on his imagination to achieve a sense of belonging, but this turns out to be "notoriously unreliable and capricious" and as a consequence a "plenitudinous sense of home" is moved out of reach because "a sense of displacement always remains" (McLeod 211). Stuart Hall sums this up concisely by saying, "Migration is a one way trip. There is no 'home' to go back to" (qutd. in Chambers 9).

Accordingly, the migrant is considered to be neither here nor there. He is alienated from his origins but does not fit in with his new environment either. His sense of belonging to a place is either disturbed or lost altogether and he is not sure of his identity anymore as a result of this. Even scholars such as Paul White who admit to the possibility that migrants can actually live in several "worlds" (3) still come to the conclusion that their experience is nevertheless marked by "dislocation" and "alienation" (6) and that "amongst all the literature of migration the highest proportion deals in some way with ideas of return, whether actualised or remaining imaginary" (14). Iain Chambers even claims that "[ $t$ he migrant's sense of being rootless, of living between worlds, between a lost past and a nonintegrated present, is perhaps the most fitting metaphor of this (post)modern condition" (27).

More recent works on postcolonial literature and theory still adhere to that view. For example, Elleke Boehmer describes migrants as people who "live as minorities, in states of unbelonging" (226). ${ }^{1}$ Echoing Ashcroft, Griffiths and Tiffin she declares that "[c]ultural expatriation is now widely regarded as intrinsic to the postcolonial literary experience" (226). Of the migrant writer she says that at present he or she is "is more likely to be a cultural traveller, or an 'extra-territorial', than a national" who most often lives in a Western country and simultaneously still keeps some "connections" to "a national, ethnic, or regional background" but whom she clearly sees as not belonging to either country (Boehmer 227). Diasporic writing by writers of the next generation who did not even migrate themselves falls in the same category for her, being "a literature that is necessarily transplanted, displaced" and even though situated in the West still not completely part of it (Boehmer 230; emphasis in original). McLeod likewise speaks of a "perilous intermediate position that both migrants and their children are deemed to occupy" because of which they are "unable to indulge in sentiments of belonging to either place" (214; emphasis in original). The repercussions of migration thus even extend to people who did not migrate themselves and it seems that having a cultural background, which spans several nations is enough to evoke inevitable feelings of dislocation.

1 Boehmer's study was admittedly first published in 1995, however the revised edition of 2005 nevertheless still emphasizes the in-betweenness of the migrant experience. 
When prominent migrants such as Rushdie or Edward Said describe their migrant experience as not only alienating but also empowering and full of new possibilities (Rushdie 15; Said xxvii), this is often criticized as an elitist attitude. For example, Boehmer states that such feelings only apply to a small number of welleducated migrants who profited from moving to a "more comfortable location in the wider neo-colonial world" (231; see also Griem 269). She further claims that such migrant literature is characterized by "historical "weightlessness" as the following quote details:

In summary, postcolonial migrant literature can be described as a literature written by élites, and defined and canonized by élites. It is writing which foregrounds and celebrates a national or historical rootlessness - what the migrant Czech writer Milan Kundera might call lightness - sometimes accentuated by political cynicism. Yet, viewed from a different angle, weightlessness could also be interpreted as an evacuation of commitment, or as a dilution of those fiery concerns which originally distinguished postindependence writing. To define a literature of migrant floating as the culmination of the postcolonial must inevitably represent a diminution in a long tradition of self-consciously political writing. (Boehmer 233)

For Boehmer, current postcolonial migrant writing is clearly inferior to earlier postcolonial literature that was engaged with national concerns (Boehmer 225). For her, not showing a rootedness in specific nations appears to equal a transition to apolitical and weightless writing. ${ }^{2}$ Moreover, she claims, its weightlessness is what makes this literature much more popular in the West than postcolonial writing with "a more national focus" (Boehmer 233). This echoes a general criticism towards recent postcolonial literature that it is supposedly marked by inauthenticity (Innes 197-98) and "centred on, and largely catering to, the West" (Huggan, qtd. in Innes 199). Such postcolonial writing is accused of being of little importance to readers in the authors' countries of origin since its focus on topics such as hybridity and alienation through migration supposedly does not concern nonWestern readers without a migrant background. However, it is assumed that this particular subject matter in turn opens up possibilities of publication and recognition in the West (Huggan, qtd. in Innes 198). While a critique of such selective publishing and funding is certainly not unjustified, C.L. Innes doubts the generality of such claims by pointing out that Chinua Achebe's Things Fall Apart, which has a clear national focus and is nevertheless a canonical postcolonial text, is also

2 Boehmer nevertheless admits that there are political cosmopolitan fictions, naming Arundhati Roy's The God of Small Things as one of them, and says that she overdramatized the situation in the above quote to point out the "basic distinctions" (233). 
most often sold to readers in Africa (199) so that the choice of topics in recent postcolonial writing seems to be more complex. ${ }^{3}$

Michael Ondaatje's writing has also been included in this debate. On the one hand, his fiction has been described as being marked by "a series of international influences where cultures blend into one another with the continuous movement and accidental meetings of peoples across the globe" (Bowers 153). On the other hand, Ondaatje could easily be found guilty of weightlessness and lack of commitment because of that and his work be seen as a celebration of rootlessness. In fact, Arun P. Mukherjee accuses him of exactly this and asks, "[H] ow has Ondaatje managed to remain silent about his experience of displacement or otherness in Canada when it is generally known to be quite a traumatic experience?" (50). Mukherjee unites both strands of criticism towards postcolonial migrant writing in this: Ondaatje is seen guilty of betraying his Sri Lankan roots because he does not write about his alienation in the West. In addition, Mukherjee's criticism that Ondaatje does not address typical migrant concerns oddly emphasizes the stereotypical restriction of acceptable topics in literature by migrants. It is surprising that Mukherjee does not also explicitly accuse him of being elitist which would not be far-fetched considering Ondaatje's celebration of his family as part of a Ceylonese elite in Running in the Family. ${ }^{4}$ In any case, Mukherjee's critique exemplifies the rigid nature of the debate about migrant writing in postcolonial literary studies: writers like Ondaatje who do not adhere to an accepted way of writing about the experience of migration are ruthlessly criticized. This is not to say that it is justified to read such a literature as a celebration of the effortless blending of different cultures as Maggie Ann Bowers appears to be doing. Neither extreme does these texts justice. It appears that there are texts that do not fit the conventional categorization and that new perspectives are needed to analyze such writing.

In order to escape these dichotomous approaches it is necessary to focus on the subtleties of these texts and to consider literature from a cultural studies perspective and not only a political one. As White argues, literature echoes "the circumstances that lead to its creation" (15). Debbie Lisle also supports this claim, stating "a cultural product cannot be understood in isolation from its social and political environment" (17). This necessarily leads to the question of whether this kind of migrant literature was created in a different context altogether in which there was no dominant "traumatic experience" and that it maybe does not celebrate the rootlessness of a displaced, unbelonging migrant but that it reflects de-

3 For a discussion of the influence of market forces on topics in and publishing and funding of minority literatures see for example Mahlete-Tsigé Getachew's essay "Marginalia: Black Literature and the Problem of Recognition" (332 ff.), and Barbara Godard's analysis of the marketing of minority literatures in Canada (226 ff.).

4 Admittedly, Mukherjee only addresses the lack of attention to migrant concerns in Ondaatje's early writing. While Ondaatje's later texts increasingly focus on migrants and their questions of displacement and identity, he nevertheless still avoids talking directly about his immigration experience so that Mukherjee's criticism would most likely still apply. 
velopments of the time of its creation. One must therefore transcend disciplinary boundaries and examine this literature's background: contemporary migration.

International migration is continually on the rise. The United Nation's Department of Economic and Social Affairs listed an estimated 191 million international migrants in its 2005 population stock database, which constitutes an increase of 115 million since 1965 (United Nations, "Estimated"). In other words, at present three percent of the world's population are international migrants which makes it the highest since the beginning of the UN's recordings (United Nations, "International Migrants"). The number of migrants would "constitute the fifth most populous country in the world" ("Global Estimates"). Accordingly, the International Organization for Migration calls migration "one of the defining issues of the twenty-first century" since "more people are on the move today than an an other point in human history" ("About Migration"). Scholars predict that international migration will continue to rise in the future (Hollifield 77; Castles and Miller 8) and have even gone as far as calling the present age "The Age of Migration" (Castles and Miller). Migration clearly is an important aspect of more and more people's lives.

Necessarily, such a huge number of migrants will lead to diverse migrant experiences. For a start, there are many different incentives for migration, which do not always make it a voluntary endeavour. Many of today's international migrants are refugees ("Global Estimates"). An even larger number of people will have migrated because of economic necessity, which accounts for the fact that 15-20 percent of all migrants are "unauthorized migrants" and also the "large increase" of migrants to Western countries ("Global Estimates"). Such migrants might certainly be influenced by neocolonial tendencies as Boehmer indicated (231) and their negative experience may not be reflected in a migrant literature of a writer such as Rushdie who celebrates the positive aspects of his exile (s.a.). ${ }^{5}$ In addition, the influence of all these migrants on the countries of immigration must not be underestimated as Innes remarks (193). Thus, for example "Britishness" is altered to include aspects of the immigrants' culture (Innes 196). Insisting on the inevitable displacement and unbelonging of migrants seems dubious in this context.

I therefore agree with McLeod that "conventional ways we use to think about ideas such as 'belonging' no longer work" because they are based on "clearlydefined, static notions of being 'in place', firmly rooted in a community or a particular geographical location" (214). Nevertheless, I do not share his conclusion that migrants are always "in-between" for whom "[h]ome is a problematic concept" (216) because another trend in contemporary migration, namely the "[e]mergence of transnational migration" ("About migration"), considerably changes conceptions of home, identity and belonging for those affected by it so

5 The destructive influence of neocolonial forces is nevertheless not completely absent from recent migrant literature. Kiran Desai's The Inheritance of Loss and Hari Kunzru's Transmission, for example, are very critical of the neocolonial influences on contemporary migrants' lives. 
that there is no longer a focus on the in-betweenness and displacement of migrants but their transnational identities, which in turn is also reflected in migrant writing. To illustrate these changes it is, however, at first necessary to elaborate on the concept 'identity' and new transnational perspectives of migration.

\subsection{Identity}

Identity is a term notoriously difficult to define. As Rogers Brubaker and Frederick Cooper say, it "tends to mean too much (when understood in a strong sense), too little (when understood in a weak sense), or nothing at all (because of its sheer ambiguity)" (1). "As a tool for analysis, 'identity' thus becomes hardly usable because the concept has become so vague (Brubaker and Cooper 6). This stems mostly from the mingling of 'identity' as a "category of analysis" and as a "category of practice" with the latter comprising the usage of the term "by "lay" actors in some [...] everyday settings to make sense of themselves, of their activities, of what they share with, and how they differ from, others" (Brubaker and Cooper 4). Unfortunately, when it comes to analytic categories, the two categories are often mixed up which results in "an uneasy amalgam of constructivist language and essentialist argumentation" so that even many of those theorists who reject the notion of a fixed identity at the same time nevertheless use it as a practical category (Brubaker and Cooper 6$).{ }^{7}$ Some unravelling of the term 'identity' is therefore in order to make it usable as an analytical term.

To clarify the many different meanings that can be encompassed by 'identity' Brubaker and Cooper attempt to classify different types of it and finally differentiate between five "key uses" of 'identity' (6). I will quote three of them in full since they apply distinctly to the problematic formations of transnational identities that I am going to focus on and illustrate the complexity of the problem. These are defined as follows:

2. Understood as a specifically collective phenomenon, "identity" denotes a fundamental and consequential sameness among members of a group or category. This may be understood objectively (as a sameness "in itself") or subjectively (as an experienced, felt, or perceived sameness). This sameness is expected to manifest itself in solidarity, in shared dispositions or con-

6 "Strong" and "weak" here refer to understandings of the term 'identity' as "essentialist" or "constructivist" respectively (Brubaker and Cooper 2). "Strong" notions of identity thus presume that it is marked by "sameness over time or across persons" (Brubaker and Cooper 10) whereas "weak" notions describe it as "multiple, unstable, in flux, contingent, fragmented, constructed, negotiated" (Brubaker and Cooper 11). For the history of the change of usage of 'identity' see Brubaker and Cooper, 2-4.

7 Unfortunately this is also the case in postcolonial theory. I will discuss this below in connection with Bhabha's notion of hybridity. 
sciousness, or in collective action. This usage is found especially in the literature on social movements; on gender; and on race, ethnicity, and nationalism. In this usage, the line between "identity" as a category of analysis and as a category of practice is often blurred.

3. Understood as a core aspect of (individual or collective) "selfhood" or as a fundamental condition of social being, "identity" is invoked to point to something allegedly deep, basic, abiding, or foundational. This is distinguished from more superficial, accidental, fleeting, or contingent aspects or attributes of the self, and is understood as something to be valued, cultivated, supported, recognized, and preserved. This usage is characteristic of certain strands of the psychological (or psychologizing) literature, especially as influenced by Erikson, ${ }^{8}$ though it also appears in the literature on race, ethnicity, and nationalism. Here too the practical and analytical uses of "identity" are frequently conflated.

$[\ldots]$

5. Understood as the evanescent product of multiple and competing discourses, "identity" is invoked to highlight the unstable, multiple, fluctuating, and fragmented nature of the contemporary "self." This usage is found especially in the literature influenced by Foucault, post-structuralism, and postmodernism. In somewhat different form, without the post-structuralist trappings, it is also found in certain strands of the literature on ethnicity notably in "situationalist" or "contextualist" accounts of ethnicity. (Brubaker and Cooper 7-8; emphasis in original) ${ }^{9}$

The problem is obvious: all these definitions claim to stand for the term 'identity' but they clearly describe very different and even mutually exclusive things. While the second definition argues that 'identity' is something that always stays the same and never changes this is already negated to some extent in the third, which states that only some aspects never change. The fifth definition then defines 'identity' as not at all stable but as a constant process so that there appears to be hardly any sameness at all from one moment to the next, which clearly contradicts the second definition. It also becomes apparent that the use of identity with regard to nations is usually one that stresses continuity. It is thus clearly the kind of perception of identity which leads to the assumption that migration and its accompanying disruption of said sameness necessarily leads to a crisis of identity as previously mentioned.

8 Erik Erikson, mentioned in a previous passage as the theorist who "was responsible, among other things, for coining the term 'identity crisis"' (Brubaker and Cooper 2).

9 The first and fourth definitions stress the use of 'identity' as "the basis of social or political action" (Brubaker and Cooper 6) and to describe group solidarities that lead to "collective action" (Brubaker and Cooper 7-8) neither of which I will be concerned with in the following. 
Furthermore, 'identity' is used to describe group as well as individual conditions since definition two speaks of a "collective phenomenon" whereas definition five focuses on the "contemporary "self" and definition three unites both aspects. ${ }^{10}$ This is especially problematic as one's personal identity is often linked to a collective identity, such as nationality or a certain culture (Horatschek 276) but not necessarily in the same definition of identity. One can easily imagine that one admits the possibility that someone's personal identity is somewhat fluid as described in definition five but that they are part of a collective identity which stresses a "perceived sameness" among its members as in definition two. Yet, the term 'identity' is used for all of these different definitions alike so that if one comes across it in some theoretical text one can often only guess at which sense and which category is used and what exactly is meant by it.

To circumvent this confusing usage and have better analytical tools, Brubaker and Cooper therefore propose three groups of "alternative terms" which capture aspects that are generally covered by the term 'identity' (14). 'Identity' can thus stand for processes of "identification and categorization" (Brubaker and Cooper 14). This encompasses identification and categorization of oneself and of or by other people as well as "by powerful, authoritative institutions", for example a nation-state (Brubaker and Cooper 15). In this sense 'identity' appears to be mainly concerned with the act of naming or being named and the (self-) ascription of certain facts to an individual.

This is quite different from the second group under which Brubaker and Cooper subsume the terms "self-understanding and social location" (17). 'Selfunderstanding" is defined as "one's sense of who one is, of one's social location, and of how (given the first two) one is prepared to act" (Brubaker and Cooper 17). The emphasis on "social location" here is important since people define and understand themselves in relation to social connections of varying intensity surrounding them, for example via religious practices and other traditions (Brubaker and Cooper 17-18). This group differs from the first by stressing more "subjective" understandings people have about "themselves and their social world" (Brubaker and Cooper 17). It may, however, be influenced by identification and categorization by others and is not necessarily stable over time (Brubaker and Cooper 18). The second group therefore brings with it new facets of an individual's behaviour in relation to their environment and how they feel about themselves in relation to the place they inhabit in their social world. McLeod sums this

10 One might add that the condition described in the fifth definition is clearly not only used to describe individuals' identities but also that of larger groups. For example, Stuart Hall's definition of cultural identity describes it as "not a fixed essence at all, lying unchanged outside history and culture" but on the contrary as something which "is always constructed through memory, fantasy, narrative and myth. Cultural identities are the points of identification, the unstable points of identification or suture, which are made, within the discourses of history and culture. Not an essence but a positioning" (226; emphasis in original). Hall clearly speaks of a group phenomenon here. 
up succinctly: "Individual and collective identities are things which we fashion for ourselves to a degree; but they are also fashioned by others for us, whether we like it or not" (226).

Brubaker and Cooper's third group further stresses the aspect of interaction between oneself and others to form one's identity. It is made up of the terms "commonality", "connectedness" and "groupness" (Brubaker and Cooper 19). In Brubaker and Cooper's definitions commonality indicates having "some common attribute" while connectedness is meant to describe "the relational ties that link people" (20). Together these two can give rise to groupness, which is characterized by "the sense of belonging to a distinctive, bounded, solidary group" and is supposed to convey a stronger attachment than connectedness or commonality alone (Brubaker and Cooper 20). The focus of this last group is clearly on collective identities and attempts to explain what makes people feel that they belong to one specific group but not another and also the extent of such a sense of belonging as the interdependence of connectedness, groupness and commonality points out.

Brubaker and Cooper stress that none of the groups alone signifies what is usually covered by 'identity' (14). However, reversing their perspective, these three groups can be seen as building blocks of what is generally called 'identity.' In addition, cut down to their basics, they obviously address the very topics much migrant writing is concerned with when it speaks of migrants' problems with their identities: the sense of self, the relationship one has to the place one inhabits, and the sense of belonging to a bigger group one is a part of such as a specific culture or nation. In addition, the fact that 'identity' is not merely something that just is but also something that is ascribed to you by others will offer a useful tool for analyzing the more problematic aspects of transnational identities. Therefore, Brubaker and Cooper's alternatives to 'identity' are very helpful since they are much more specific and make it easier to focus on certain aspects that are usually rolled up in the term 'identity.' They furthermore also make it possible to speak of 'identity' in more than one definition without being forced to add lengthy qualifications of the term to specify what is meant. It is hence now possible to clearly analyse the problems that result from migration and transnationalism and be more specific than only speak of a crisis of identity or a changing sense of self.

Nevertheless, I am still going to speak of 'transnational identities' in the following and I will do this deliberately. I completely agree with Brubaker and Cooper that "[c]onceptualizing all affinities and affiliations, all forms of belonging, all experiences of commonality, connectedness, and cohesion, all self-understandings and self-identifications in the idiom of 'identity' saddles us with a blunt, flat, undifferentiated vocabulary" (Brubaker and Cooper 2). However, when it comes to the changes wrought by transnationalism and migration the term 'identity' is nonetheless useful as an umbrella term to sum up all the different processes that consequently occur in order to comprehend the magnitude of the phenomenon. There- 
fore, whenever the term 'identity' is used from now on it will denote the changes of all the above aspects of 'identity' combined.

\subsection{Identity and the Nation-State}

When speaking of transnational identities it is inevitable to think about nations first. After all, a transnational activity not only transcends the nation but it is also where they begin as people live in nation-states. However, a nation-state is not only a starting point for migratory movements, it can also function as a source of identity as the following quote by Steven Vertovec points out in which he describes a commonplace, more traditional understanding of the nation-state concept:

[A]s with the conventional model of the nation-state, some sense of identity is presumed to characterize a people; this identity/people is believed to be contiguous with a territory, demarcated by a border; within the border, laws underpin a specific social and political order or system; this social order which is conceived to be different from orders outside the border - both draws upon and reinforces the sense of collective identity. Identitiesborders-orders are legitimated and reproduced through a system of narratives, public rituals and institutions, educational materials, formal state bureaucracies and informal social relationships, written and unwritten regulations, sets of assumptions, and expectations of civility and public behaviour[.] ("Migrant Transnationalism" 158) 11

The nation-state here categorizes its members by imposing laws and social orders and by influencing them through education and expected norms. This categorization and identification in addition stresses the commonality of the people within the state and leads to the conclusion that people within the state differ from those outside its borders because those have different norms, rules and social behaviour. The nation-state's members accordingly develop a sense of belonging and are thus linked to their respective nation-state by "ties of sentiment" (Vertovec, "Migrant Transnationalism" 156). In more everyday terms, the nation-state becomes their home.

Ulf Hedetoft and Mette Hjort extensively reflect on the emotional implications of what it means to feel at home somewhere. Similarly to Vertovec they state that "home is where we belong, territorially, existentially, and culturally, where our own community is, where our family and loved ones reside, where we can identify our roots, and where we long to return to when we are elsewhere in the world"

11 Vertovec here sums up the findings of Civil Enculturation: Nation-State, Schools and Ethnic Difference in Four European Countries, a compilation of essays he edited along with Werner Schiffauer, Gerd Baumann and Riva Kastoryan. 
(Hedetoft and Hjort vii).12 The nation-state's relation to such notions becomes even clearer in Ulf Hannerz' definition of the term 'home.' He speaks of 'home' as being a "familiar social space because we have it quite well mapped - even the people we do not know personally act in more or less expected ways" (219). For him, it is marked by "relative transparency in social traffic" for the one whose home it is and to which, because of time spent there, we "develop a sense of belonging" (219). 'Home' in this sense is clearly marked by commonality with and connectedness to the people in one's social location. Because of this, being home is to experience a certain feeling of groupness and since this groupness is furthermore linked to a specific territory because of "identities-borders-orders", 'home' is located in the nation-state.

It is obvious that this groupness stems in part from the "narratives, public rituals and institutions" and so forth mentioned above. However, all this is not simply imposed by the nation-state in order to strengthen a "sense of collective identity" but the state also "draws upon" it according to Vertovec's definition. This implies that there is a "collective identity", which seems to precede and justify the formation of the nation-state. Ernest Renan refers to this when he stresses that a nation is made up of two aspects of which one is "a rich legacy of memories" and the other "present-day consent, the desire to live together, the will to perpetuate the value of the heritage that one has received" (19). These memories and heritage clearly indicate that the nation-state is accordingly not only understood as a person's home but also becomes an entity which encloses a group of people joined together by common traditions or a shared culture, which unites its members because its commonality stresses their similarities. This in turn allows them to connect to one another and evoke feelings of groupness. Since this groupness is, however, also confined to a specific geographic area, the nation-state thus becomes congruent with a specific culture, which can be seen best in the way the words 'nation' and 'nation-state' are used interchangeably (Brennan 45).

The nation-state thus has a powerful influence on people's sense of who they are and where they belong since according to such a definition it turns into an allencompassing source of all aspects of identity. After all, in this understanding of a nation, the nation-state is formed because its members already have a sense of collective identity prior to its formation which is strengthened after its formation because it then reiterates and reinforces what already brought this group together by identifying and categorizing its members. The inhabitants in turn can hardly escape being influenced in their self-understanding by these surroundings. It is therefore not surprising that it is frequently pointed out that in the twentieth century the nation came to be seen as home, and people's sense of belonging was generated by nation-states (J. Hall 55; Löfgren 259).

12 However, they admit that this definition only "delineates the contours of an ideal state of affairs" and that home and belonging are much more complicated in reality since the aforementioned notions can be in conflict with each other (Hedetoft and Hjort vii-viii). 
Nevertheless, it is also obvious that this understanding of the nation-state centres only on one very specific notion of identity, which is marked by commonality and sameness and disregards all other possibilities, which do not fit this theory and has been increasingly subject to criticism. Especially postcolonial and feminist critics have pointed out that such definitions of nation-states neglect to mention minorities and marginalized groups and construct a homogeneous view, which does not actually exist (Horatschek 276). Furthermore, it has been pointed out that from a historical perspective the existence of nation-states is a rather new phenomenon with its starting point located in Europe between the late eighteenth and early twentieth century (Anderson 4; Beck, "Globalisierung" 51-52; During 139). ${ }^{13}$ Especially Benedict Anderson has pointed out the socially constructed nature of nation-states. He illustrates that a nation is most of all an "imagined community" because "the members of even the smallest nation will never know most of their fellow-members, meet them, or even hear of them" (6).

Yet, even without face-to-face contact the nation-state's members still feel connected to one another (Anderson 6). This "deep, horizontal comradeship", as Anderson calls it (7), leads to identification with the nation-state and a sense of groupness among the nation's members. Even though this unity is to a great extent only imagined it regardless makes the nation-state a real entity as can be seen from the huge number of people ready to "not so much kill as willingly die" for it as Anderson puts it (7). This pertains to the "emotional legitimacy" of the nation (Anderson 4) and shows its members' identification with it and their selfunderstanding and social location in the nation. However, Brubaker and Cooper also emphasize that the nation-state is "a powerful 'identifier,' [...] because it has the material and symbolic resources to impose the categories, classificatory schemes, and modes of social counting and accounting with which bureaucrats, judges, teachers, and doctors must work and to which non-state actors must refer" (16). A nation-state, whether one sees it as imagined or not, thus holds a great amount of very real power over its members in that it can identify and categorize, whether they feel particularly emotionally invested in it or not.

When it comes to migration these things get complicated. For a start, if the nation-state and thus a specific territory is seen as a person's home, a migrant must inevitably be homeless because he or she is separated from it. Migrants consequently must be literally displaced and since commonality, connectedness and groupness are joined to the place they left, they are also separated from all familiar social space, which in turn must have a significant impact on their selfunderstanding. In addition, they are confronted with the confusing situations that there are now several nation-states competing in their attempts to categorize and identify. It seems that the crisis of identity, which is so frequently invoked by

13 The exact dating is disputed. Anderson argues for the late eighteenth century. During situates it slightly later in the early nineteenth century. Beck on the other hand links it to the rise of the discipline of sociology and accordingly dates it to the nineteenth and early twentieth century. 
postcolonial theorists is inevitable. As by now has become quite obvious this results from the assumption that identity is necessarily tied to territory. However, contemporary social science shows that there has been a profound change in "social, territorial, and cultural reproduction of group identity" (Appadurai 48) so that old definitions of home and belonging consequently do not apply to "an increasing number" of people anymore (Hannerz 218). This realization follows from a shift in the view of migration because of which the focus is not so much on international migration anymore but on transnational migration and the concomitant changes of nation-states through transnationalism.

\section{Transnationalism}

\subsection{New Perspectives on Migration}

Past migration research used to predominantly analyse the way immigrants adjusted to their new life in the country they emigrated to. Their continuing ties and connections to their country of origin were mostly neglected (Vertovec, "Transnationalism and Identity" 574) or even thought to eventually stop altogether (Glick Schiller, Basch and Szanton Blanc, "From Immigrant" 73; Wong and Satzewich 3). As already touched upon in the previous chapter, sociologists had simply assumed that the "rise of the nation-state" had confined people's social lives "within its borders" (J. Hall 60).

Underlying this assumption was the so-called "container-theory of society" which assumes that each society is enclosed in a separate nation-state just as in a container (Beck, "Globalisierung" 49; my translation). Ludger Pries explains that this theory results from a particular perception of 'space' in sociology in which a distinction is made between "social space" and "geographic space" (3). ${ }^{14}$ According to this, "social space" signifies people's social interactions in their daily lives and their connections to others, whereas "geographic space" describes a particular territory (Pries 3). Sociologists believed that social space was tied to geographic space and as a result "society was conceived as a territorial unity, usually constituted as a nation-state" (Pries 16). Since, in addition, migratory movements were thought to be "unidirectional and one-time changes in location" theorists presumed that if people migrated they left one container for another and necessarily had to break their connections to the old container (Pries 21).

Such a view of migration accordingly did not allow for the possibility of continued involvement in the home country since from such a perspective cultural and social participation is only possible if one is in the place a particular society

14 This is of course only a small fraction of the usage of 'space' in sociology. For a comprehensive overview see Pries 6-20. 
inhabits. As the possibility of return was ignored, the physical separation from a nation-state necessarily meant that the existing connection just stopped. Even though research on migrant diasporas showed that connections to the homeland often remained, they were nevertheless accentuated by feelings of loss and unbelonging. James Clifford thus characterizes diasporas as marked by "a history of dispersal, myths/memories of the homeland, alienation in the host (bad host?) country, desire for eventual return, ongoing support of the homeland, and a collective identity importantly defined by this relationship" (305). ${ }^{15}$ Even though Clifford stresses that not all of these criteria have to apply at the same time (306), it is nevertheless obvious that the relationship to the country left behind is still very important for the diaspora's members and that they feel both non-belonging in their new country and disconnected from the old one to which they wish to return. In Clifford's words, "diaspora communities are 'not-here' to stay" and exist in a state of "living here and remembering/desiring another place" (311). This closely resembles postcolonial critics' view with their emphasis on imaginary homelands which replace the real home country after migration. Yet,as shown above this phantasm proved equally futile and lead to disillusionment on migrants' return. Confronted with these alternatives it is no wonder that migrants were thought to only have the option of either assimilating to their new location or of feeling deterritorialized and alienated.

However, research done in the social sciences since the 1990s shows that this view of migration and its effects upon migrants was not entirely correct. Some of the earliest scholars who noted this were the cultural anthropologists Nina Glick Schiller, Linda Basch and Cristina Blanc-Szanton. Studying the lives of "migrants from Haiti, the eastern Caribbean, and the Philippines" who had migrated to New York, Glick Schiller, Basch and Blanc-Szanton observed that many of these migrants were still - and often to a great extent - involved in the affairs of the countries they had left ("Transnationalism" 2). These continuing ties were manifested in diverse actions such as sending back money to their families, owning property in the sending country, investing money in community building projects or taking part in politics there (Glick Schiller, Basch and Blanc-Szanton, "Transnationalism" 2). In addition, they frequently travelled back and forth between the two countries (Glick Schiller, Basch and Blanc-Szanton, "Transnationalism 3). They were wellestablished in their lives in New York and took part in local politics there as well as in the country they had migrated from (Glick Schiller, Basch and BlancSzanton, "Transnationalism" 3). In such a case one can no longer speak of migrants as exiles who do not fit in with both the sending and the receiving coun-

15 Robert Smith points out that lately the term 'diaspora' has been applied differently "to describe the state of dispersal and connectedness between migrants and their homelands" with no further regard for Clifford's other points (190). 
try. ${ }^{16}$ Glick Schiller, Basch and Blanc-Szanton therefore concluded that the container theory of nation-states did not adequately capture the reality of many migrants' lives and that new research categories were needed ("Transnationalism" 5). They furthermore believed that contemporary migrants can be distinguished from former generations in so far as " $\mathrm{t}]$ heir lives cut across national boundaries and bring two societies into a single social field" (Glick Schiller, Basch and BlancSzanton, "Transnationalism" 1). According to them, contemporary migrants are not simply ordinary immigrants but "transmigrants" who "take actions, make decisions, and feel concerns, and develop identities within social networks that connect them to two or more societies simultaneously" (Glick Schiller, Basch and Blanc-Szanton, "Transnationalism" 1-2). Thus it appears that integration into a new country and transnational connections with the old one are not mutually exclusive practices. In the case of these migrants the connection between social space and geographic space has been weakened.

Other researchers have been quick to critically point out that transnational migration is not an entirely new phenomenon. For example, Christiane Harzig and Dirk Hoerder in their study "Transnationalism and the Age of Mass Migration, 1880 s to 1920 s" prove that transnational activities existed already much earlier among migrants from Europe who migrated to North America. ${ }^{17}$ However, Glick Schiller, Basch and Blanc-Szanton also acknowledge that there was earlier transnational activity, but clarify that the receiving state generally attempted to suppress such actions because they "raised questions about the allegiance and loyalty of immigrants" ("From Immigrant" 80). ${ }^{18}$ Hence, scholars have recently appeared to view transnational migration not as a new phenomenon per se but rather as a new perspective on international migration (Portes and DeWind 10; Vertovec, "Transnationalism and Identity" 576-77). Regardless, in spite of the disagreement about the starting point of the phenomenon it is apparent that it is of far greater extent than originally imagined. In addition, there seems to be a growing consensus that contemporary transnational migration has a different quality because advances in technology make travelling and communication easier (Hannerz 225; Portes and DeWind 10-11; Vertovec, "Migrant Transnationalism" 149-50). The latter makes

16 There are definitely parallels between such behaviour and the behaviour of members of diasporas. However, most of the characteristics of diaspora do not fit: these migrants are not alienated in the host country, there is no dispersal, myth of the homeland and desire for eventual return because the homeland is not something from which they are cut off. Consequently, their "collective identity" (Clifford 305) is not shaped by the experience of dislocation. Lloyd Wong and Vic Satzewich therefore call diasporas "a concomitant of transnationalism" but they encompass additional different aspects (5-6). They also admit that there is a difference in scope between the two (Wong and Satzewich 6), which I will address in the next chapter.

17 Paul Kennedy and Victor Roudometof provide a concise summary of various other critical voices regarding the historical perspective of transnationalism (2-3).

18 In other articles Cristina Blanc-Szanton is listed differently as 'Christina Szanton Blanc'. To avoid confusion, I will continue to refer to her as 'Blanc-Szanton' in the text. 
the means for transnational behaviour accessible to a greater number of people and not only a small elite. Therefore, modern transnational migration is often described as "a phenomenon of ever-greater intensity and scope" (Jackson, Crang and Dwyer 11).

What exactly is considered transnational behaviour differs widely from one approach to the next. While initially the focus was mainly on nation-state transcending connections of migrants, Peggy Levitt and Nina Glick Schiller by now differentiate between four different "traditions" of research in transnationalism which vary widely in scope and focus (183). ${ }^{19}$ The areas of interest in these fields are very diverse and span questions of economic and political incentives for transnational migration, the role of gender in it, its effects on families, the emergence of migrant networks, migrants' assimilation or non-assimilation to the new country, and reactions of sending and receiving countries towards transnational migration, to name only a few of the topics covered (Levitt and Glick Schiller 183-85).

Moreover, the general use of the concept has become even more widespread and has often been used to characterize the behaviour of "all migrants, [...] every ethnic diaspora, [...] all travellers and tourists" as Vertovec complains ("Transnationalism and Identity" 576). It is hardly surprising that the term 'transnationalism' is thus often found in connection with qualifiers such as "over-used" (Vertovec, "Transnationalism and Identity" 576), "elastic" and "stretched" (Wong and Satzewich 2). It seems that almost any kind of action or person can be labelled 'transnational' and as a result the term appears to have been stripped of all meaning at times. To specify my use of the term I will therefore limit myself to one approach to transnationalism in the following which strikes me as particularly useful with regard to aspects of identity formation because of its focus on the reconfiguration of social space.

\subsection{Transnational Social Space}

Transnational migration clearly shows that geographic space and social space are not necessarily congruent anymore. From the beginning, Glick Schiller, Basch and Blanc-Szanton stated that transnational migrants "live in and create a new social and cultural space" ("Transnationalism" 14) and argued that it was necessary to concentrate on transnationalism in terms of "a new field of social relations" to adequately describe the concomitant changes ("Transnationalism" 19). Many others have subsequently taken up this social fields perspective (e.g. Beck, "Globalisierung"; Jackson, Crang and Dwyer; Kennedy and Roudometof; Pries; Vertovec) and recently Levitt and Glick Schiller have attempted to generalize the results of

19 For detailed information and further reading on these different groups see Levitt and Glick Schiller 183-85. Peter Jackson, Philip Crang and Claire Dwyer also offer a compact overview of different forms of and research approaches to transnationalism (8-11). 
this in what they call "a transnational social field perspective on society" (Levitt and Glick Schiller 181). They show that in contrast to the container model of societies with its impermeable borders social fields are:

a set of multiple interlocking networks of social relationships through which ideas, practices, and resources are unequally exchanged, organized, and transformed [...]. Social fields are multidimensional, encompassing structured interactions of differing forms, depth, and breadth that are differentiated in social theory by the terms organization, institution, and social movement. National boundaries are not necessarily contiguous with the boundaries of social fields. (Levitt and Glick Schiller 188)

This perspective allows for greater accuracy in the analysis of migrants' social behaviour, which is not limited by national borders. After all, as Vertovec points out, for transnational migrants "[a]spects of life 'here' and life 'there' [...] are constantly monitored and perceived as complementary aspects of a single space of experience" (Vertovec, "Migrant Transnationalism" 153-54) which could hardly be captured if the focus was solely on particular nation-states. Transnational migrants thus take part in several worlds simultaneously (Harzig 51; Levitt and Glick Schiller 182; Vertovec, "Migrant Transnationalism" 149-50). Accordingly, the social field perspective opens up a new space which does not limit social interactions to either here or there but rather focuses on a state of being both here and there at the same time (Beck, "Globalisierung" 58). ${ }^{20}$ This perceived simultaneity of lives in geographically separated places is one of the most important aspects of this theory.

Moreover, the focus on transnational space does not only offers a new perspective of migrants' lives, but also depicts the wider implications of transnationalism. It becomes apparent that non-migrants are equally affected by these developments and can take part in transnational social space as well through contact with migrants. Much research has been done on this aspect. Hence, Harzig and Hoerder stress that "both worlds overlap in communities of origin, too" because of migrants' continued involvement in their countries of emigration (43). ${ }^{21}$ Transnational migration, for example, generates the development of networks between migrants and non-migrants in the sending country (Hollifield 78; Levitt and Glick Schiller 191; Portes 6). These facilitate migration because they "help to lower the costs and the risks of migration" and also further intensify the linkage of both countries (Hollfield 78).

20 Beck speaks of this space as "etwas Neues, Drittes", a third space, as opposed to the two states of 'here' and 'there' ("Globalisierung" 58). This inevitably evokes Homi Bhabha's concept of the third space which is, however, quite different from Beck's and on which I will elaborate below.

21 This seems to be more pronounced in more recent forms of transnationalism, though, because of technological advances (Harzig and Hoerder 44). 
Research has less focused on the participation of non-migrants in transnational social space in the receiving country. Jackson, Crang and Dwyer emphasize how the existence of minority groups or diasporas can also influence people in the host country through day to day contact and enable them to enter transnational social space. They propagate a very inclusive notion of transnationalism in which one can already temporarily enter transnational space by consuming ethnic food (3). While this may seem far-fetched at first, it can nevertheless imply that there is contact and exchange between a diasporic or transnational population in a country and people who have no migrant background or experience and therefore can be seen as an, albeit minor, transnational occurrence. This aspect is more pronounced in Arjuan Appadurai's theories on global flows. While Appadurai does not hold a transnational view but rather sees the increase of global interconnection as the beginning of the end of nation-states (19), his study on the influence of the media on people's imagination indicates how people are connected transnationally through the media. For Appadurai, the imagination "creates ideas of neighbourhood and nationhood" (7) and shared imaginings result in border-crossing "communit[ies] of sentiment" (8). Similar to Anderson's "imagined communities", Appadurai calls these shared imaginings people's "imagined worlds" which are made up of members all over the world (33). According to this, shared media consumption can unite people who are territorially far apart in common transnational social space. Thus if immigrants watch, for example, a home TV programme while living abroad they become part of "diasporic public spheres" (Appadurai 4). However, such connections are not only imaginary but also bring with them the possibility for real contact with another geographically removed culture.

It must be stressed that not all migrants lead transnational lives (Vertovec, "Transnationalism" 576). Nonetheless, the predicted further increase in international migration and the consolidation of transnational communities is thought to also lead to an exponential rise of transnational migration (Portes 9-10). In addition, although for many people culture and community is still tied to place (Jackson, Crang and Dwyer 6-7) the number of people who will take part in transnational social space, whether they have a background of migration, or not will necessarily also increase since migrants influence their receiving countries (Jackson, Crang and Dwyer 2; Kennedy and Roudometof 5). Social space and geographic space are not congruent anymore for even more people than previously presumed and this number is increasing. Hannerz therefore concludes that " $\mathrm{f}$ ] or a growing number of people, of several kinds, personal border-crossing involvements with different places, cultures, and nations can be central, deeply affecting experiences" (230).

The question that begs to be asked now is how these developments affect people's identities. After all, the orderly state model with clearly demarcated "[i]dentities-borders-orders" that Vertovec had lined out is obviously strongly impacted by this since more and more people lead lives that cut across borders, 
and thereby change orders and identities ("Migrant Transnationalism" 158). Even theories on diasporic communities or imagined homelands do not entirely cover this phenomenon of continued simultaneous involvement in both country of immigration and sending country. Both rootedness in a nation-state and uncertain ideas of home in diasporas thus do not adequately capture the realities of people who live in transnational social spaces for whom questions of identity, home and belonging certainly bring up very different answers.

\section{Transnational Identities}

\subsection{Hybridity}

A long neglected influential concept must finally be acknowledged: hybridity. Especially in postcolonial literary theory one can hardly escape the term, above all when it comes to migrants' identities, which are generally described as hybrid. My only using it sparingly in this thesis therefore needs some explanation. In cultural studies, the concept of hybridity is used to describe the effects on identities in the case of contact between different cultures (Griem 269). It is an attempt to go beyond the conception of cultural identities as absolutes, which is illustrated by the notion of the "third space" which shows how cultures interpenetrate one another and become inextricably intertwined (Griem 269; my translation). This approach is highly influenced by the writings of Homi Bhabha. However, Bhabha's definition of hybridity is quite problematic. As Ania Loomba puts it, it is not only the "most influential" but also the "most controversial in postcolonial studies" (148). Nevertheless, it is inevitable to address it in connection with transnationalism, since hybridity also speaks of the migrant condition in terms of space.

The problem with Bhabha's use of hybridity becomes instantly apparent as soon as one tries to point out how Bhabha defines hybridity since he hardly ever says what it is but mostly just what it does. For him "all forms of culture are continually in a process of hybridity" ("Third Space" 211), and, while different from one another ("Third Space" 209), they are constantly "subject to intrinsic forms of translation" ("Third Space" 210). ${ }^{22}$ As he explains in "The Third Space", when such intrinsically hybrid cultures meet, a hybridizing process starts:

[T] he importance of hybridity is not to be able to trace two original moments from which the third emerges, rather hybridity to me is the third

22 Bhabha defines 'translation' as "a way of imitating, but in a mischievous, displacing sense imitating an original in such a way that the priority of the original is not reinforced but by the very fact that it can be simulated, copied, transferred, transformed, made into a simulacrum and so on: the 'original' is never finished or complete in itself. The 'originary' is always open to translation so that it can never be said to have a totalised prior moment of being or meaning an essence" ("Third Space" 210; emphasis in original). 
space' which enables other positions to emerge. This third space displaces the histories that constitute it, and sets up new structures of authority, new political initiatives, which are inadequately understood through received wisdom. [...] [H]ybridity puts together the traces of certain other meanings or discourses. It does not give them the authority of being prior in the sense of being the original: they are prior only in the sense of being anterior. The process of hybridity gives rise to something different, something new and unrecognisable, a new area of negotiation of meaning and representation. (Bhabha, "Third Space" 211)

According to this, hybridity is a process which leads to the creation of "something new" that does, however, contain some "traces" of what existed before its creation, but is neither one nor the other. Being a mixture of both it is nevertheless neither. For Bhabha, this is how new cultural meaning is produced. An important notion connected with that of hybridity is that of liminality. Hybridity comes into existence in the "third space", which Bhabha also often calls an "'in-between" space ("Location" 2), especially when he refers to contact between nations. When different national cultures, which he stresses are not homogeneous or pure to begin with ("Location" 212), come into contact with one another, they enter into the process of hybridization. This takes place at "the boundary [which] becomes the place from which something begins its presencing" ("Location" 7; emphasis in original). Thus the "boundary" is the place of contact where hybridity is created and consequently the place at which the third space is located.

This boundary is however used in a metaphorical sense and does not denote a "physical location" (Huddart 7). Therefore, the liminal, in-between space of the boundary becomes a "space in which strategies for personal or communal selfhood may be elaborated, a region in which there is a continual process of movement and interchange between different states" (Ashcroft, Griffiths and Tiffin, "Liminality" 130). As Bhabha also assumes that all cultures are constantly changing within during the process of inner translation, the whole concept becomes slightly paradoxical since then everything turns out to be hybrid. One must wonder of how much more use this concept can be once the constructed nature of cultures, identities and nations has been recognized (see also Easthope 346; Griem 269). In addition, Bhabha's purely theoretical approach neglects the very real power of nation-states to identify and categorize, which puts an end to at least some aspects of hybridization when it comes to national identities.

This is made even more problematic by the lack of differentiation of hybridity in Bhabha's theory. As stated, for Bhabha, hybridization occurs whenever there is contact between differences. This clearly does not only apply to collectives such as nations or cultures, but necessarily also affects individuals and especially migrants. Yet, all Bhabha says of such migrants is that they occupy "'in-between' spaces" ("Location" 2) and the spaces of "liminality" ("Location" 321). They are displaced (Bhabha "Location" 13) and lead "unhomely" lives which means that they do not 
entirely belong since they are always located at the border (Bhabha "Location 13). The only characteristic of Bhabha's migrant figure appears to be his displacement. Loomba therefore understandably complains:

$[D]$ espite the accent on hybridity and liminality, Bhabha generalises and universalises the colonial encounter. Thus, ironically, the split, ambivalent, hybrid colonial subject projected in his work is in fact curiously universal and homogeneous - that is to say he could exist anywhere in the colonial world. Hybridity seems to be a characteristic of his inner life (and I use the male pronoun purposely) but not of his positioning. He is internally split and antagonistic, but undifferentiated by gender, class or location. (149$50)^{23}$

Such a use of hybridity can of course only result in generalizations about a wide range of possible different but interrelated phenomena. For example, if it was applied to merely the changes in identity formation through transnational migration there would hardly be any differentiation between the impact it has on different aspects of identity if one only spoke of hybrid identities. I am therefore somewhat reluctant to use the term 'hybridity' as it is imprecise, lacking in meaning and also automatically equates hybridity with displacement. Furthermore, it does not offer any differentiation in the quality of hybridity which makes the concept appear oddly static and the emergence of hybrids inevitable so that terming someone's identity 'hybrid' carries hardly any meaning at all as, on further reflection, everybody's identity is hybrid. It does not seem likely, though, that all those who are caught in cross-cultural or transnational situations would react in the same way to it, so that regarding contemporary migration and its effects, ,transnational' seems to be a more adequate qualifier when speaking of identities.

In addition, the term also reflects the continuing power of nation-states, making it less abstract than hybridity. After all, while identities are no longer solely dependent on the nation-state, and home and belonging are no longer automatically confined to one nation-state, it nevertheless hardly seems that "the nationstate, as a complex modern political form, is on its last legs" as Appadurai claims (19). While the nation-state's influence has surely weakened through transnational behaviour it has not altogether disappeared (Jackson, Crang and Dwyer 11; Wayland 19). The majority of researchers denies the advent of postnational ways of life because after all "people are not deterritorialized but live their lives on earth, in states, and in communities" (Wayland 20; see also Yeoh, Lai, Charney and Kiong 2). True global belonging would only be available to a very small elite who has the pecuniary means to afford constant travelling all over the world (Hedetoft and Hjort xviii). Thus, for the majority the globe is not "something people belong to"

23 While Loomba restricts Bhabha's use of hybridity to the colonial context, it also applies to migrants since Bhabha's later works have become considerably wider in scope and include contemporary problems (Huddart 124 ff.). 
as Hedetoft and Hjort explain (xx; emphasis in original). Accordingly, local attachments cannot simply be ignored like Bhabha does.

\subsection{Changes in Identity Formation}

What then do transnational identities look like? They are no longer confined to a single nation-state, but also not postnational. Therefore, concerning identification and categorization, transnational individuals identify with several nations and cultures, which they feel they belong to. Hannerz accordingly speaks of "'biterritorialization', or 'multiterritorialization"' (220), which Beck very aptly calls "place polygamy" ("Living" 276) thereby emphasizing the feeling of belonging to several places or nations at once. There can now be two or more nation-states who can exercise the power to identify and categorize (or not), which can result in dual or multiple citizenship, which is, however, not practiced in all states (Wayland 26). ${ }^{24}$ Even if it is, it is not without its problems as Levitt and Glick Schiller point out:

First, dual belonging calls into question the very notion of governance because it is not readily obvious which state is ultimately responsible for which aspects of transnational migrants' lives. Where should those who live across borders get health care, pay taxes, or serve in the army? Which state assumes the primary responsibility for migrants' protection and representation? What happens when migrants are sentenced to the death penalty in their host country while the death sentence is prohibited in their country of origin? (204)

These are all very important questions with no readily available answers so far. The nation-state's power to categorize and identify its members is thus somewhat weakened because it is shared and because a specific nation-state's authority is not automatically guaranteed anymore. Nevertheless, Levitt and Glick Schiller look at this not as a loss of power but rather a transformation of the state which now "assumes new functions" (198)..$^{25}$

Self-understanding and social location underwent considerable change, too. While one's social location is not tied to a particular place anymore, people still live in certain places and communities, as emphasized above. However, for transmigrants their social location can differ markedly from one actual location to the next. Levitt and Glick Schiller thus point out the possibility that "individuals occupy different gender, racial, and class positions within different states at the same time" (194). For example, people may be well educated or belong to a high social class in their home country, but nevertheless work in low paid jobs in the host

24 Since citizenship, rights, and participation will not be of great importance in the following, I will not go into detail here. Levitt and Glick Schiller provide a good overview (197-205).

25 See previous note. 
country (Levitt and Glick Schiller 194-95), which would accordingly influence the way they act in these respective social locations. Such cases also indicate that transnational behaviour is not only a phenomenon of elites as postcolonial theorists claim, who can easily switch between countries since they certainly would not experience differences in social location as drastic.

In addition, as one's social location is also influenced by the identification and categorization by others, transmigrants might experience rejection, for example in the form of racism, by not being identified as part of one of the nations or cultures which make up their social space (Glick Schiller, Basch and Blanc-Szanton, "Transnationalism" 18) which would lead to feelings of displacement. Transnational lives can nevertheless also be empowering, especially for those whose countries occupy less privileged positions in the world. They can increase their influence in the home country as their social location can change for the better through migration because it can offer them possibilities to both improve the standing of themselves and their home country economically (Levitt and Glick Schiller 192). It furthermore enables them to advance changes for their benefit in both sending and receiving states (Levitt and Glick Schiller 193).

Furthermore, non-migrants' social location and self-understanding can also be influenced if they are involved in transnational social space. As the examples from the previous chapter have shown such involvement can be quite significant in its influence on the sending country's economy, for example because of money transfers. Additionally, the contact between those who stayed behind and temporarily or permanently - returning migrants leads to the formers' acquaintance with a transnational lifestyle which can have "a powerful impact even on the transnational orientations of those who have never left" (Vertovec, "Migrant Transnationalism" 155). Similarly to Appadurai, Levitt furthermore points out that through the media Western culture has already so much influence on non-Western countries that today's migrants "arrive already partially socialized" to the new country's culture (25).

Transnational migration can even lead to changes in the political structure of both sending and receiving countries. Levitt and Glick Schiller point out the example of governmental structures:

Migrants bring ideas about governance with them that transform hostcountry politics, they reformulate their ideas and practices in response to their experiences with host states, and they communicate these social remittances back to those in their homelands or members of their networks settled in other states. (205)

Such behaviour inevitably influences the social and political structure of both states, which would in turn force non-migrants in the receiving countries to adapt to the changes. In addition, Levitt and Glick Schiller give examples of how transnational migrants influence their host countries to interfere with the domestic 
politics of their country of origin (193). Further influences can be discerned on an interpersonal level because the presence of migrants with different cultural traits can lead to "transculturation" when these differences are incorporated in the place they inhabit (Chan and Ma 12). All of this clearly leads to changes in selfunderstanding, which is linked to one's social location. If the one undergoes a drastic change, the other can hardly remain uninfluenced.

This leaves the aspects of commonality, connectedness and groupness and with it the question of where transnational people belong. As with all of the above, possibilities have also multiplied here. Hence, transnational migrants are described as having "multiple attachments" (Hedetoft and Hjort xvi), "multiple membership and multiple loyalties" (Kastoryano 134). Similarly, Wong describes that they have "deep attachments to more than one "home" (170) while others again stress that the concept of 'home' is not necessarily linked to a specific place any longer (Yeoh, Lai, Charney and Kiong 7). Rather, transmigrants have "a more 'itinerant' or 'portable' notion of 'home"' (Yeoh, Lai, Charney and Kiong 7) just as they "construct and utilize flexible personal and national identities" (Yeoh, Lai, Charney and Kiong 3). Adaptability and multiplicity appear to be the general characteristics of such belongings. Ayse Çağlar sums this up precisely by observing that transnational migrants "weave their collective identities out of multiple affiliations and positionings. They link their cross-cutting belongingness with complex attachments and multiple allegiances to issues, peoples, places and traditions beyond the boundaries of their resident nation-states" (610). Similarly, selfidentification also becomes a more complex issue because transnational migrants "incorporate cultural references from both the place of origin and the place of residence" as Sarah Wayland notes (18). Levitt and Glick Schiller nevertheless stress that such transnational activities do not hinder assimilation into the country of immigration but can occur simultaneously (182).

Moreover, the identities may also change over time. Levitt and Glick Schiller accordingly distinguish between "ways of being" and "ways of belonging" in/to a transnational social field (187). They note that it is possible to be part of a social field but to decide not to "identify with any label or cultural politics associated with that field" (Levitt and Glick Schiller 189). One would then merely be part of the field, but not belong to it and thus be engaged in "ways of being". "Ways of belonging" on the other hand imply that one acts in such a way as to show a "conscious connection" to the field (Levitt and Glick Schiller 189). The emphasis here is on "concrete, visible actions" that signify the belonging to that field (Levitt and Glick Schiller 189). Ways of being and belonging can change over time and also depend on particular situations (Levitt and Glick Schiller 189). For example, a migrant might stay in touch with people in the home country, but not identify with the country at all, and would thus exhibit "transnational ways of being but not belonging" (Levitt and Glick Schiller 189-90). This person can, however, also revert to ways of belonging when they begin to "explicitly recognize this and high- 
light the transnational elements of who they are" (Levitt and Glick Schiller 190). Transnational identities are therefore not "linear or sequential" but can alter over time in their intensity and there are degrees of connection regarding the countries involved (Levitt and Glick Schiller 190). This certainly offers a much more detailed perspective with regard to the identities of those involved than 'hybridity' could by highlighting that becoming transnational is not an event but an intricate process.

So far there have been few critical voices concerning transnational lives. That such networks of complex belongings and allegiances always work smoothly can hardly be expected, though. Satzewich and Wong voice concern that maybe states may not always be positive and accommodating towards transnational activities and wonder if "in an era of shifting global alliances when yesterday's international ally can quickly turn into today's 'rogue state' (and vice versa)" the pursuit of transnational connections may be rather risky (298). A significantly larger group of theorists believe that transnational lifestyles will increase, affect more and more people regardless of their migrant status and thus change societies all over the globe so much that "transnational lifestyles may become not the exception but the rule" (Levitt 4; see also Beck, "Living" 275; Hannerz 230; Hedetoft and Hjort xvi; Wong 170). In such a scenario all nation-states, cultures and lives would eventually become hybrid, in the sense of being mixtures of different influences (Beck, "Living" 280; Chan and Ma 15).

\section{Transnational Identities in Ondaatje's Fiction}

I will start my interpretation of Ondaatje's fiction with a quote that refers back to chapter 2. In an essay on The English Patient Aitor Ibarrola-Armendariz comments on the state of North American literature:

[L]ately the very heart of North American literature has been taken over by a race of postnational authors characterized by their rootlessness and sense of transcultural identity. [...] Rather than seeing their existence divided between their old home and indigenous heritage and a new home in a postimperial order, they prefer to (un)define themselves as belonging to two or more - half-homes simultaneously. Naturally, their literary production is deeply affected by this change in self-perception, so that what we generally encounter in it are groups of uprooted souls, their lives dominated by an all-prevailing sense of dislocation. (37-38)

As above, migrant writing is again seen as dislocated and uprooted and its characters - as well as the author - as having no real home and celebrating their rootlessness. Especially when it comes to Ondaatje's fiction, such a judgement seems unconvincing to me and appears to merely repeat the usual concerns associated with migrant writing without taking a closer look. I will not the deny the existence 
of the typical migrant writing motifs in Ondaatje's books as there certainly are instances when his characters seem unsure of where they belong and who they are and when they feel dislocated. If one approaches these texts with a different focus - on the transnational aspects of the characters' identities - the analysis must result in a quite different interpretation. Through such a lense one can see that in Ondaatje's fiction complex questions of post-, trans-, or simply national belonging, self-understanding, and connectedness are negotiated in subtle yet precise ways that are never uncritical. On the contrary, the texts do not offer simple, clear-cut answers to these issues and by this defy the categories that are usually applied to migrant literature.

In order to capture these aspects of the novels and show how they differ from other forms of migrant writing, I will therefore now analyze them with the help of the results from the previous theoretical part. The different aspects of transnational identities will be pointed out in the migrant characters in Ondaatje's fiction so that it will be possible to examine different approaches to transnational identities that are juxtaposed, compared and contrasted. Special attention will also be paid to the transnational spaces, metaphoric and real, that the characters are located in because repeatedly the use of spaces, their boundaries, dissolution and overlapping in the texts reflects the same questions concerning identities in highly symbolic ways. As a result, the representation of characters' identities in Ondaatje's fiction often almost seems like a direct engagement with the theoretical concerns of transnational studies, relocated to a fictional arena, as the following analysis will show.

\subsection{Anil's Ghost and Running in the Family: Journeying towards Belonging}

Anil's Ghost and Running in the Family do not only share a similar plot revolving around a return journey to the protagonists' country of origin, they are also equally concerned with questions of identity. ${ }^{26}$ Both protagonists, Anil Tissera and Michael Ondaatje, the narrator of Running in the Family, are migrants whose lives have lead them across the boundaries of several nation-states. ${ }^{27}$ However, while this situates both of them in a transnational social field, neither character seems aware of that or particularly interested in a transnational life up to the point when they suddenly feel the need to return. In Levitt and Glick Schiller's terms, they are engaged in transnational ways of being but not belonging. When they eventually do engage in a journey to the country they came from this turns out to be not only a literal journey but also a symbolic one in which they have to relocate the

26 The texts will in the following be abbreviated as $A G$ and $R F$.

27 Running in the Family is by admission of its author a fictionalized account of two journeys to Sri Lanka in 1978 and 1980 (Running in the Family 205-6) so that the narrator must be strictly separated from the author Michael Ondaatje. Unless stated otherwise 'Ondaatje' will refer to the narrator of Running in the Family in chapter 5.1. 
boundaries of their social space in order to establish a transnational mode of belonging. This proves difficult and frustrating though, as crossing the borders of nation-states, even a war-torn one in Anil's case, is much easier than crossing the cultural and historical ones that keep them separated from their past. In addition, crossing into a transnational way of belonging is presented as coming with its own set of difficulties in Anil's Ghost, which makes it (the author) Ondaatje's most critical book concerning transnational identities.

\subsubsection{Dealings with Boundaries}

Initially, the characters Anil and Ondaatje appear to be much alike. Their lives read like ordinary, but rather successful immigration stories. Anil is a renowned scientist, Ondaatje a famous author. Both seem to lead equally successful, welladjusted lives in Western countries. Even their immigration stories sound similar. Ondaatje, having left Sri Lanka at the age of ten for England, later moved on to Canada, where he stayed permanently ( $R F$ 172). Although not much is said in the text of his feelings towards Canada, he appears at home there with friends and family ( $R F$ 22) and there is no mention of alienation and feeling displaced. ${ }^{28}$ As Danuta Woznialis rightly remarks, it is "his other country and the motherland of his children" (278). Similarly, Anil left Sri Lanka to study in England and after that moved on to the United States ( $A G$ 145). When asked about her affiliations, she states, “I live here,' [...] 'In the West." (AG 36). Neither one of them appears to strongly identify with their home country anymore but for different reasons: the beginning of striking differences between these two characters.

Ondaatje matter-of-factly admits that he had "slipped past a childhood [he] had ignored and not understood" (RF 22). This neglect appears to have happened accidentally and is hardly surprising since most of his family crisscrossed the globe repeatedly: "Gilian stayed in Ceylon with me, Christopher and Janet went to England. I went to England, Christopher went to Canada, Gilian came to England, Janet went to America, Gilian returned to Ceylon, Janet returned to England, I went to Canada." (RF 172). They were never again all in the same place together (RF 172). Ondaatje's social space was thus necessarily disconnected from geographic space since his family connections occurred transnationally. With the family scattered, home and belonging appear to be more tied to people than to a particular place, and since only one sister and the estranged father stayed in Ceylon the connection to the country and any sense of connectedness to its culture naturally weakened.

28 There has been much debate concerning the genre of Running in the Family, which I will not go into here. As already mentioned, the book is a partly fictionalized account, but otherwise hard to classify and will therefore here only be referred to as 'text' or 'book'. For discussions of the genre of Running in the Family see Smaro Kamboureli, "The Alphabet of the Self: Generic and Other Slippages in Michael Ondaatje's Running in the Family." 
This is very different from Anil's story as she downright rejects national belonging soon after she has left Sri Lanka. While at first feeling alienated and lost in England and so homesick that she marries another Sri Lankan ( $A G$ 142), little later she deliberately tries to break her connections with Sri Lanka without showing clear reasons for doing so. As long as her parents are alive she still has some feelings of connectedness to Sri Lanka, which are superficial, though: "her only real connection was the new sarong her parents sent her every Christmas (which she dutifully wore), and news clippings of swim meets" ( $A G 10)$. This remnant of belonging to Sri Lankan culture is more obligation than her own freel will, though, since "dutifully" engaging in a cultural practice hardly indicates belonging by choice. She "courted foreignness" ( $A G 54$ ), stopped speaking Sinhala and "turned fully to the place she found herself in" ( $A G$ 145). However, this place is not a country or a culture but science ( $A G$ 145). The scientist community she becomes part of appears to her to be its own "world" with its own culture, which Anil is fascinated with ( $A G$ 147). It is also the only larger group which she connects to emotionally. She admits that she "would always love the clatter and verbal fling of pathologists" ( $A G$ 148), "loved their rituals" (147) and took part in their "old tradition" of listening to music while working ( $A G$ 146). She is clearly very attached to it, identifies with it and probably feels she belongs there.

This scientific community is transnational in its own right since its members come "from all over the world" (AG 36) and are bound together by the same interest. It is what Appadurai would call a "community of sentiment" which exists independent of national boundaries, without any particular affiliation to specific nations (8). This, however, makes it more postnational than transnational as the geographic space of this community seems completely interchangeable as can be seen in Anil's vague responses to where she lives. She feels at home in the world of science, which is not limited to a particular place while admitting her affiliations with nations only in the vaguest terms. She "now travelled with a British passport" (AG 15-16) and resides in the West ( $A G$ 36) but any emotional attachment to a country as a whole that would show that she understands herself as part of it is strangely missing (see also Danyte, qutd. in Woznialis 280). ${ }^{29}$ Thus, while she could be identified as British, her self-understanding would most likely differ. Even when she contemplates returning to the "adopted country of her choice" ( $A G$ 285) at the end of the novel one cannot be quite sure whether she means the country whose passport she carries or the one in which she lives. Her lack of specificity in this perfectly reflects what she says she likes about the West: anonymity ( $A G 72)$.

29 Nevertheless, she feels attached to certain localities, such as Oklahoma, which she loves because of its deserts ( $A G$ 149). This is immediately contrasted with the flowering, green Sri Lankan landscape in which "she could spit on the ground and a bush would leap up" (AG 148). Her love of deserts is thus another instance of deliberate disconnection from Sri Lanka. 
Both characters are thus engaged in transnational ways of being but at first but do not make the deliberate choice of belonging. Indeed, Anil appears to have even moved beyond emotional attachments to countries and national cultures altogether and lives in the postnational space of science without any interest in being transnational. However, both characters change their ways and set out on very different return journeys, running towards their country of origins in Ondaatje's case or starting to hesitantly move in its direction in the case of Anil, which is symbolized in a number of border crossings.

For Ondaatje, the incentive to return is a dream about his father in which he sees him in the jungle surrounded by barking dogs ( $R F$ 21). Waking up, the "bright bone of a dream" still lingers and has long-lasting effects on the narrator:

The noises [of the barking dogs] woke me up I sat up on the uncomfortable sofa and I was in a jungle, hot sweating. Street lights bounced off the snow and into the room through the hanging vines and ferns at my friend's window. [...] Tense, not wanting to move as the heat gradually left me, as the sweat evaporated and I became conscious again of the brittle air outside the windows searing and howling through the streets and over the frozen cars hunched like sheep all the way down towards Lake Ontario. It was a new winter and I was already dreaming of Asia. (RF 21-22)

The passage is marked by strong contrasts between heat and cold which are associated with Asia and Canada respectively and point out differences between the countries (see also Pesch 58; Ray 41). It also locates the narrator in a symbolic transnational space in which aspects of Asia and Canada are simultaneously present. After all, the narrator does not remember having been in a jungle in his dream, but in the instance of waking up he "was in a jungle" and with the vines and ferns at the window the jungle appears to invade the Canadian winter. Places which are geographically far apart as well as mutually exclusive elements are suddenly united in the space of the friend's living room.

The moment affects the narrator profoundly and functions like an epiphany that makes him suddenly aware that these contrasts are united in himself as well. As Joanna Saul observes, the passage shows that "[t]he here and there are in constant dialogue, so that the often naturalized relationship between self and place is interrogated. Ondaatje discovers that he is neither 'Sri Lankan' nor 'Canadian' in any straightforward way" (43). I slightly disagree with her on this, however, since the fusion of time (the father's past), place (Sri Lanka and Canada) and contrasting elements (fire, ice) in the familiar space of the living room of all rooms, seem to indicate that the narrator encompasses both. The dream therefore turns into an indicator of his transnational self, which transcends geographic spaces and national boundaries. It is this discovery that starts the narrator's "running" to Asia (RF 22) and in doing this the decision to reconnect with previously neglected aspects of his transnational identity. The passage accordingly not only marks a 
change in his self-understanding but also the beginning of a literal journey to Sri Lanka in order to reconnect with his country of origin in order to understand the newly found transnational self. In addition, the dream is the first of many instances that confront the narrator with various boundaries and their crossing or at least attempts at doing so.

The starting point for Anil's decision to re-connect with her Sri Lankan identity is harder to pin down. Her initial request to go on a human rights investigation to Sri Lanka had been "halfhearted" ( $A G 15)$ and once she arrives she seems to be unsure about how to proceed. Even though Anil has some relatives left in Colombo she decides not to contact them ( $A G$ 10). Moreover, she makes it very clear that she is "not a prodigal" $(A G 10)$ and dislikes being connected to her past as a famous swimmer ( $A G$ 16). By this she refutes any connectedness to the country. ${ }^{30}$ This is also demonstrated in her - erroneous - belief that " $\mathrm{t}[\mathrm{h}] \mathrm{e}$ island no longer held her by the past" ( $A G$ 11). She does not understand herself as Sri Lankan. As Woznialis remarks, "she seems to have decided to go to her motherland as a foreigner" (280). Even though she later admits that she "decided to come back [...] wanted to come back" (AG 200) she attempts to look at Sri Lanka with a "long-distance gaze" $(A G 11)$ and by this acts like she did with regard to her Western countries. Anil appears to have walled herself off from national and therefore also transnational groupness or connectedness and seems unwilling to remove these barriers between herself and the world. Not unfittingly, David Farrier describes the life she led in the West as a "somnambulant existence" because of its utter lack of deep and meaningful connections (84). She seems to be completely oblivious to anything outside the world of science with its sterile labs. She is awoken from this sleep by the resurfacing of long-forgotten memories from her childhood in Sri Lanka, which can be seen as a first boundary crossing experience for her as the memories manage to escape her subconscious. They make her realize that there is, or at least once was, more to her life than just science and she feels that she must face the "background" she had previously ignored and refused to address ( $A G$ 36), which results in her hesitantly changing her selfunderstanding.

\subsubsection{Confusion and Isolation}

As Saul rightly says, there is a "theme of searching [...] at the heart of Running in the Family" (37) and this description certainly also applies to Anil's Ghost. The searches are quite different, though. Ondaatje sets out to discover his family history, and especially the father he hardly knew, to find his "roots" in the country

30 Woznialis points out that when Anil begins to identify with Sri Lanka again in the end she does no longer reject her labelling, even refers to herself as "the swimmer" (AG 270) and thereby "reinstates her old identity" (282). 
(Pesch 57). Anil on the other hand searches for the truth in the war crimes she investigates. However, as Woznialis explains, "Anil's 'getting to the truth' comes to imply a struggle for self-discovery as well" (282). In addition, both quests can also be seen as struggles to overcome the boundaries that separate the characters from past aspects of their lives and show their developing a new more transnational self-understanding.

For Ondaatje, the enterprise seems simple at first since his extended family still offers him a familiar social location in the country. He thus still has a place in Sri Lankan society and can use this to learn about the family's past. It seems only a matter of collecting information through his various aunts that can then be organized into a family history (RF 26). Yet, his search is soon complicated when Ondaatje realizes that in his family "[e]veryone was vaguely related and had Sinhalese, Tamil, Dutch, British and Burgher blood in them going back many generations" ( RF 41) so that it becomes impossible to say for certain were the family's roots lie and what its nationality is. "God alone knows" as one of his relatives once said (RF 41). In addition, Ondaatje realizes that the past he put together from his sources "was part of another lost world" (RF 51) that ended with the decolonization of the island $(R F 53)$ and does not exist in this form anymore. With regard to his parents, Ondaatje furthermore recognizes that "[t]ruth disappears with history and gossip tells us in the end nothing of personal relationships" (RF 53). The past he wanted to get to know eludes him and strongly resembles the image of the "human pyramid" formed by his family members, which he saw in a dream (RF 27). Just as the pyramid naturally walks through the living-room wall, his family is not stopped by the seemingly distinct boundaries between nationalities, countries, truth and lies.

Ondaatje also realizes that present day Sri Lanka is not his home anymore. While several critics have voiced the opinion that Running in the Family is mostly concerned with creating the Ondaatjes' past as indicated in the narrator's continually calling Sri Lanka by its colonial name 'Ceylon' (Kamboureli, "Alphabet" 91; Woznialis 276) this is clearly not the case. Ondaatje likewise also reflects on his position in contemporary Sri Lanka which he encounters in his journeys. For example, in the chapter titled "Monsoon Notebook (i)" he lists impressions of every mundane detail that he sees and notices in run-on sentences:

Watched leopards sip slowly, watched the crow sitting restless on his branch peering about with his beak open. Have seen the outline of a large fish caught and thrown in the curl of a wave, been where nobody wears socks, where you wash your feet before you go to bed, where I watch my sister who alternatively reminds me of my father, mother and brother. Driven through rainstorms that flood the streets for an hour and suddenly evaporate, where sweat falls in the path of this ballpoint, where the jak fruit rolls across your feet in the back of the jeep, where there are eighteen ways 
of describing the smell of durian, where bullocks hold up traffic and steam after the rains. ( $R F$ 69)

He appears to want to write down every impression and sensation he comes across to evoke the atmosphere of the place but by his choice of topics which highlight everyday life reveals how unusual these events have become for him. As Graham Huggan observes, "he mocks his readers, and himself, for playing the part of wide-eyed foreigners" (122). It is clearly not the point of view of someone who feels naturally at home in the place Ondaatje describes but that of an outsider.

Soon, his approach does not stay this humorous but turns to frustration in the chapter called "The Karapothas" which translates as the foreigners ( $R F$ 80). At this point in the text, Ondaatje becomes aware that he is displaced in this country, which is also his homeland and states "I am the foreigner. I am the prodigal who hates the foreigner" ( $R F$ 79). His belonging or lack of belonging to Sri Lanka is paradoxical to him as he believes "[w]e own the country we grow up in, or we are aliens and invaders" (RF 81). He grew up in the country, and nevertheless is also a stranger in it upon his return and consequently a colonizer.

Ajay Heble therefore concludes that Ondaatje is "ex-centric" and assumes that Ondaatje realizes that "he himself is the other" ("Rumours" 189; also Huggan 118-19; Saul 43) which, however, provokes the questions 'Which other?' and 'Where is the centre that he is displaced from?' After all, Ondaatje is not only unable to connect to his family tradition because it existed in the bygone era of Sri Lanka's colonial past. He in addition does not fit into present-day independent Sri Lanka either. He is "other" and "ex-centric" in several ways: as a Canadian in Sri Lanka, as a Ceylonese in Sri Lanka and as both a Canadian and Ceylonese who cannot return to a stable past that would offer a locally fixed sense of belonging because this past was never stable to begin with but subject to many different influences and affiliations. A dichotomy between self and other is hence not possible anymore in his case and a clearly identifiable centre can no longer be located. ${ }^{31}$ Ondaatje's self-understanding is troubled by this because he does not know to which of these he belongs and how he can connect to them.

It is hardly surprising that the two poems following this chapter, "High Flower" and "To Colombo" (RF 87-91), focus on Sri Lankans without a mixed background whose belonging is rooted in place. While Sangeeta Ray complains that the characters are presented as "native subalterns" (43), this does not seem to

31 In her analysis of Anil's Ghost Victoria Cook similarly states, "[Ondaatje's] voice is one of those involved in re-defining the boundaries, speaking from beyond preconceptions of 'the Other' and 'writing back' to 'the West,' and reconfiguring the 'postcolonial' perspective into one of 'transnationalism.' Anil's Ghost provides a forum for the expression of a range of cultural identities - one in which the postcolonial voice does not simply speak from the margins, but is represented as an integrated component of a transnational identity" (8). This clearly applies to all of Ondaatje's fiction. 
be the poems' intent. Their position at this point in the text rather suggests that they function as a melancholic, romanticized image of people whose culture sits in place and who do not have to deal with the problem of being both foreigner and prodigal at the same time. Strikingly, the "brown men" in "To Colombo" "rise knee deep like the earth / out of the earth" ( $R F$ 90). They appear to literally have grown out of the land which Ondaatje envies at this point. These people can connect to the country in a way that Ondaatje and his hybrid family cannot (see also Leon 31). The sentimental mood is only confirmed if one takes a look at the poem "Sweet Like a Crow" preceding the chapter (RF 76-77). It describes a young Sinhalese girl singing so out of tune that her voice is described as sounding, for example, "like someone pulling barbed wire / across a stone courtyard, like a pig drowning" (RF 76). It must take a great amount of romanticizing and sentimentality indeed to construe this noise as even remotely "sweet". The poems accordingly convey Ondaatje's momentary longing for a simpler notion of home and identity resulting from his frustration in establishing a connection to Sri Lanka/Ceylon, not without his typical irony though by overdramatically exaggerating his feelings.

Anil's reconnection with her homeland is similarly difficult and shows a more complicated side of having a transnational identity as she suffers from a conflict of interests. This is best expressed in her inability to use her once native language and her inability or unwillingness to modify her idea of truth. Her reflections on language show a change in her self-understanding: she is upset that she can no longer speak Sinhala because it prevents her from communicating with other Sri Lankans, such as Ananda ( $A G$ 170) and her ayah, Lalitha. The meeting with Lalitha demonstrates this especially well. Because they no longer speak the same language, Anil cannot re-establish their relationship, which leaves both of them feeling isolated: "When Anil let go, the old woman seemed stranded [...]. Anil sat next to Lalitha and held her hand in silence, feeling an ache in herself' ( $A G$ 22). There is a border between them that they cannot cross. Anil is in this instant confronted with the extent of her estrangement from the culture she was born into. Even when she wants to belong to it again, she is unable to, which is especially painful with regard to Lalitha who is Anil's last intimate connection in the country. It is therefore not possible for herself to realign herself to the Sri Lankan part of her identity even though she wishes to.

This is further emphasized by the reaction of Lalitha's granddaughter. She watches the meeting through "stern eyes" ( $A G$ 22) and deliberately excludes Anil by talking to Lalitha in Tamil without bothering to translate for Anil (AG 23). She even pointedly highlights Anil's lack of "connection" to Sri Lanka ( $A G$ 24) and by all this categorizes Anil as an outsider who does not belong there. While this certainly mirrors Anil's self-understanding upon initially arriving on the island, it is now painful because it emphasizes a boundary between her and the woman whom she loves like a mother ( $A G$ 23) and because Anil has finally decided that she wants to cross the boundaries that separate her from Sri Lankan society but is 
unable to. Like Ondaatje, Anil thus becomes a stranger in her homeland and feels equally lost as further comments on her inability to speak Sinhala show: "on this island, she realized she was moving with only one arm of language [...]. There was less to hold on to with that one arm" ( $A G 54)$. Her ability to connect to the social world around her is severely handicapped. As Brenda Glover shows in her analysis of Anil's behaviour in Sri Lanka, her lack of language denies her a whole world (79). This certainly complicates any further attempts to establish transnational ways of belonging - or even being for that matter - because Anil is cut off from a large part of the population.

However, it is important that Anil's problem concerning language is not that she has completely forgotten how to speak Sinhala, but it is "her lack of tone" which makes it impossible for others to understand her ( $A G$ 23). There is no differentiation or nuance in her voice, which makes questions, offers and commands sound the same. This lack of differentiation is also present in other aspects of Anil's behaviour and is her biggest problem when it comes to finding her way in Sri Lankan society. Her attitude towards the concept of truth exemplifies this particularly well. Anil believes that the truth is simple and straightforward: "she had come to expect clearly marked roads to the source of most mysteries. Information could always be clarified and acted upon" ( $A G 54)$. Therefore, when she and her colleague, Sarath, discover the skeleton they dub "Sailor", she immediately thinks that this is an opportunity to accuse the government of a war crime ( $A G$ 51). She entirely overlooks the fact that the social location she is in in war-torn Sri Lanka is very different from her social world in the West and accordingly demands an adjustment of her actions. As Sarath says, "It's different here, dangerous. Sometimes law is on the side of power not truth" ( $A G 44) .{ }^{32}$ Yet, as with her language Anil has only one tone to use, and that is the 'tone' of Western science.

In the course of the investigation this leads to constant tension between her and Sarath who repeatedly accuses her of acting like a "visiting journalist" ( $A G$ 27; see also 44). This does not mean, though, that she is a "stock character in postcolonial fiction: the Europe- or America-returned professional woman struggling to maintain her hard-won status against all odds" (Burton 41). On the contrary, its symbolizes Anil's problem to form transnational ways of belonging because as soon as she takes up the nuanced changeable notion of truth Sarath offers, she is in conflict with her Western self-understanding which is above all dependent on her being a scientist as shown above.

32 Teresa Derrickson, however, remarks, "Lost in this account [...] is a summary of the foreign agenda that is served by initiating a human rights investigation on the island to begin with. As the novel tells us, the president of Sri Lanka only approved of Anil's visit in an attempt to 'placate trading partners in the West' ([AG]16). This statement not only provides insight as to why the Sri Lankan government has taken a sudden interest in the human rights of its people, but it also suggests a dubious reason as to why the United Nations has followed suit" (142). Apparently, the truth is not only influenced by power in Sri Lanka alone. 
Victoria Cook is therefore certainly right to note that "Anil's Ghost provides an examination of identity reflective of the cultural clashes that are an inevitable consequence of such an interweaving of nationalities, histories, and border divisions" (6). With regard to her understanding of truth, to belong to one country makes it impossible to belong to the other. It is impossible for her to identify with both. Thus, while Teresa Derrickson states that "the total exclusion of any other possible outcome in Anil's search for truth in Sri Lanka is somewhat troubling" (140), it is also to some extent understandable since in order to accept different notions of truth Anil would have to become a different person from the one she thinks she is. Having a transnational identity is in Anil's case a much more difficult affair than in Ondaatje's case. She does not merely have to reconnect to her homeland and negotiate a new place in it, she also has to fundamentally change her selfunderstanding. Becoming Sri Lankan again in the current circumstances makes it impossible for her to entirely be "alongside the language of science" ( $A G$ 145) which is extremely problematic for her because it is the only thing that generates a feeling of belonging and home.

\subsubsection{Collapsing Boundaries}

In a somewhat ironic reversal of other forms of migrant writing both Ondaatje and Anil feel most displaced and unsure about who they are only upon their return to their 'homeland' which is by now much less of a home than their Western countries. Yet, for both of them this confused state is not permanent but merely a stage of adjustment on their journey to find ways to break down the boundaries that separate them from the possibility of transnational belonging.

Ondaatje's change in self-understanding begins immediately after the crisis that had left him feeling displaced and unsure of his belongings and its starting point is another poem. In "Women Like You" (RF 92-94), which is significantly subtitled "the communal poem" ( $R F$ 92), the speaker describes the beauty of rock carvings in the shape of women. Admiring them he falls in love with both the women and the surrounding landscape: "Seeing you / I want no other life / and turn around / to the sky / and everywhere below / jungle, waves of heat / secular love" (RF 93). Suddenly, the perspective reverses and the speaker becomes part of the group of women so that "we stand against the sky" (RF 94). To an observer, the speaker thus becomes part of the landscape while the speaker feels a connectedness with the cultural artefact as indicated by his use of 'we'. In a following metafictional moment, he is identified as Ondaatje who says, "I bring you / a flute / from the throat/ of a loon" (RF 94). Ondaatje, the North American bird-singer-poet, offers a poem - a "flute" - to the country and by communicating with it in this way 
writes himself into the country and becomes part of its community. ${ }^{33}$ For the writer, crossing the boundary between fact and fiction, writing himself into the country, as well as into his fiction, turns out to be his route to belonging.

This practice is continued repeatedly throughout the rest of the text, the most noted example of which is a correspondence between the poem "The Cinnamon Peeler" (RF 95-97) and a later scene in which Ondaatje's father gives a cinnamon peeler a ride in his car (RF 187). As the poem starts "If I were a cinnamon peeler", Pesch takes this to mean that "the narrator slips into the role of the cinnamon peeler, but the context reveals that the love poem is also an attempt to become Mervyn's companion in conversation" (68; see also Heble, "Rumours" 199; Snelling 29). ${ }^{34}$ Thus Ondaatje has not only written himself into the Sri Lankan landscape again but also into his father's past. This is further emphasized by the description of the father sitting on the bathroom floor watching ants carrying away page 189 of a book, which corresponds exactly to page 189 of Running in the Family on which the scene is located (Kamboureli, "Alphabet" 90). Saul consequently states, "By fictionalizing his family history, by filling in missing gaps, and by adding his own voice to the versions of others, he is taking some ownership of his past" (51).

Nevertheless, Saul assumes that the fragmented form of the narrative suggests that Ondaatje is not really at home in Sri Lanka: "In the search for some kind of connection or sense of belonging, Ondaatje comes up with numerous ruptures and gaps" (53). However, she overlooks that the different and seemingly separate parts of the text are often intricately related to one another and thereby create some form of textual unity. This is done by the repetition of motifs which function as bridging devices between individual and often widely separated parts of the narrative. The cinnamon peeler has already been mentioned which links the poem

33 This writing of himself into landscape also echoes an earlier description of Ondaatje's grandfather: 'Like some other Ondaatjes, Bampa had a weakness for pretending to be 'English' and, in his starched collars and grey suits, was determined in his customs. [...] It was only in the afternoons when, dressed in sarong and vest, he went out for walks over his property (part of a mysterious treatment for diabetes), that he seemed to become a real part of the landscape around him" ( $R F$ 56). As in the poem blending into landscape signals some form of 'real' connection with one's environment here (see also Leon 33-34).

34 Ray critically remarks that the poem about the cinnamon peeler constructs the "native" as static to contrast him with the Ondaatjes' mobility. She complains, "That this mobility, a benefit enjoyed by voluntary exiles, is often enabled by those exploited and burdened by the current global economy based on international trade is entirely overlooked by Ondaatje in his poem [...]" (Ray 46). I am not convinced of this, though, since the emphasis on the smell of cinnamon relates the poem also to another scene in the book in which Ondaatje tells an anecdote about ship captains who used to sprinkle cinnamon across the ship a few miles off the coast and to ask their passengers to "smell Ceylon". Shortly after this he then continues: "This island was a paradise to be sacked. Every conceivable thing was collected and shipped back to Europe", amongst them "seven kinds of cinnamon" ( $R F$ 81). Ondaatje seems to be more aware of exploitative practices than Ray gives him credit for. 
with the father and the son's doubts about his belonging. Similarly, the initial "bone of a dream" that initiated Ondaatje's journey in Canada (RF 21) comes up again towards the end of the book in the chapter "The Bone" (RF 182). Another example is the wild pig which Ondaatje sees during a trip to the jungle, where he feels so at home in Sri Lanka, that the pig becomes "my wild pig" (RF 142-43; see also Leon 34). The pig conspicuously also is part of the poem "To Colombo" (RF 90) with its emphasis on having roots in the place. The book therefore is not as fragmented as it seems at first but relies strongly on linking devices that make it a unified whole. If the story is taken as a symbol for transnational belonging as Saul takes it, then it also stands for the interconnection of different parts, which are contained in a transnational identity. While " $\mathrm{h}]$ is writing act does not disperse the chaos of the dream that set him running" (Kamboureli, "Alphabet" 87) it turns out to be much less chaotic than it at first appeared.

For Anil a reconciliation of the differences between her countries is not so easily achieved. In her case it is not really possible to belong to both because being part of one group betrays the other. Transnational belonging for her comes with a price. When she in the end identifies with Sri Lanka, and announces in front of a group of government officials "I think you murdered hundreds of us" ( $A G$ 272) she clearly states her affiliation with the country and engages in transnational ways of belonging since she still believes in Western truths. As Sarath observes, her speech is "a citizen's evidence; she was no longer just a foreign authority" ( $A G$ 272). This also turns her into a threat to the authorities, though, and she suffers the consequences. Farrier accordingly points out, "It is important to note that after declaring her commonality with Sri Lanka, Anil is repeatedly strip-searched as she leaves the government building, demonstrating the vulnerability of intimacy, how it can lead to intrusion and deprivation" (90). At this point the boundary between her and Sri Lanka has disappeared, she is now part of it. But by becoming Sri Lakan again she is also stripped of part of her former identity.

Derrickson assumes that after this incident Anil will return to the West and "the story [she] will ultimately tell about the 'truth' of Sri Lanka is a Western story" (136). Her identification with the country does not seem to end with her leaving, however. Her reflections on her time in Sri Lanka show how ambivalent she feels about her newfound connection with her old country. When she remembers a conversation she had with Sarath and his brother Gamini, she ponders:

If she were stepping into another life now, back to the adopted country of her choice, how much would Gamini and the memory of Sarath be a part of her life? Would she talk to intimates about them, the two Colombo brothers? And she in some way like a sister between them, keeping them from mauling each other's worlds? Wherever she might be, would she think of them? ( $A G$ 285) 
This reflection takes place after the events narrated in the novel have ended since Sarath is already dead. Only his "memory" remains whereas Gamini who is alive could in reality be a part of Anil's life. In addition, Anil seems to be still in Sri Lanka and undecided whether she should leave or not. She has not yet disappeared like the hero of Western novels who leaves the country after his job is done and does not care anymore what happens there as Gamini dismissively points out: "So the war, to all purposes, is over. That's enough reality for the West" (AG 286). For Anil, however, the war is not so easily over. Another passage states, "Anil would never get over her time here" ( $A G$ 202). It has deeply influenced her because she feels both Sri Lankan and Western at the end of the novel but in her case, having a transnational identity and identifying with both cultures left her feeling conflicted and uneasy because her experience has shown her that not all differences can be reconciled. She nevertheless does not reject her transnational identity. The text indicates that she returns to the country: "Years later she might see an etching or a drawing and understand something about it, not sure why - unless she were told that the walawwa she lived in had belonged to the artist's family and that the artist had also lived there for a time" ( $A G$ 202). The connection and identification with the country has obviously not stopped even years later. Thus, unlike Ondaatje's, Anil's transnational ways of belonging highlight that transnational identities can be a very complicated and unsettling affair.

\subsection{In the Skin of a Lion: Transformative Space and the Narrative of the Self}

"I will wander through the wilderness" reads the first epigraph of In the Skin of a Lion, and it could hardly capture the novel's main theme better, since this is a story of wanderings, or, in other words, of migration. Almost all characters in the novel engage in some form of migration from the Finnish loggers in Patrick's childhood to Ambrose Small, Clara and, of course, the immigrant community Patrick encounters in Toronto. As in Anil's Ghost the peregrinations and migrations are also journeys towards forming transnational identities during which the characters struggle to find their place in Canadian society and come to terms with their initial feelings of displacement. However, in In the Skin of a Lion forming transnational identities is not only reflected in the characters' migrations but especially in symbolic transformative spaces they are located in.

\subsubsection{Actual and Metaphorical Migrations}

In the Skin of a Lion's theme of migration is most prominently embodied in the characters of Patrick Lewis and Nicholas Temelcoff whose migration experiences act as a foil for one another. While Temelcoff immigrates to Canada from Macedonia, Patrick's move from rural Ontario to Toronto is also presented as an im- 
migration experience when he is explicitly referred to as an "immigrant to the city" (In the Skin of a Lion 53). ${ }^{35}$ Patrick's immigration is further emphasized when he begins to live in Toronto's immigrant quarter in which he is identified as an "alien" (SL 113) so that he becomes a "foreigner in his own country" (Gorjup 92). As Simone Vauthier comments, "By a neat inversion, Patrick Lewis, who by virtue of his birth and native tongue, not to mention gender, belongs to the dominant group, is made an outsider" (72). To Patrick, entering the immigrant community is like metaphorically migrating to another country even though he never left his home country. While Patrick's immigration is thus not entirely real because he does not move from one country to another it certainly is an entering into transnational social space.

As a result, both Patrick and Temelcoff find themselves in socially and culturally different places and initially struggle with similar questions of identity, which are mostly expressed through their use of language (see also Bölling 214; Schumacher 13; Stolar 127-28; Vauthier 71). They cannot connect to the new communities surrounding them at first because they lack the language to do so and are isolated from others. This is expressed in both characters' unawareness of the people surrounding them. So Temelcoff believes no one can hear or see him while he works on the bridge ( $S L$ 42), just as for Patrick his neighbours in Toronto's immigrant quarter are merely "dark blinds on his street, their street" (SL 113). Consequently, this "linguistic and cultural exile" (Gorjup 92) leads to an impaired self-understanding, which can be seen in Temelcoff's being described as having "no portrait of himself" (SL 42) while Patrick is "new even to himself" (SL 54). They are not sure anymore who they are and where they belong. There is certainly no sense of developing transnational identities here but on the contrary a strong sense of general dislocation, which is in line with traditional forms of migrant writing except that strangely a character who is not a real migrant is also affected by this.

There has been much criticism of the equation of Patrick's and Temelcoff's situations, especially since Patrick, in an attempt to become part of the immigrant community, conceals his identity as a Canadian and does not speak around the English-speaking overseers at work (SL 136). Therefore, some have pointed out that Patrick is in a privileged position because he has a choice not to speak while the immigrants' inability to communicate is involuntary because they do not know English (Bölling 214; Vauthier 73). Others are offended that Patrick feels "deliriously anonymous" (SL 112) in his exile, which they see as self-imposed whereas for the immigrants it is a harsh reality from which they cannot escape (Kamboureli, "Culture" 49). Dennis Duffy consequently argues that the immigrants' anonymity makes them "disenfranchised" and "vulnerable" to the authorities (134) and Jody Mason accuses Ondaatje of "effac[ing] important differences

35 In the Skin of a Lion will from now on be abbreviated as SL. 
among kinds of travel and degrees of agency" (75). According to her, Temelcoff and Patrick's travels are "clearly radically different" (Mason 70) because Patrick has "greater agency than any of the other migrant characters in the novel" since he was born in Canada (Mason 72). This, however, is not entirely true and their juxtaposition is much more subtle and subversive.

Patrick obviously has more rights and opportunities than the immigrants because he can be categorized as a citizen of the state. The immigrants do not seem to have citizenship which makes them dependent on the goodwill of the authorities. In addition, while the immigrants' inability to speak English certainly poses a disadvantage for them and denies them the means to be heard and thus to establish some sense of connectedness to their new country, Patrick's knowledge of the language theoretically allows him to speak up, connect and become part of the English-speaking majority. Yet, in practice this is not the case and Patrick is as disconnected from his co-nationals as from the immigrants. As Karen Overbye demonstrates, Patrick is generally " 'inexpressive' in his relationships with others" (5) which is mentioned repeatedly in the text when even in situations with English-speaking people Patrick keeps his distance from them. During his relationship with Clara "[h]e liked to sleep separate, in his own world" (SL 65), and he feels that he is always "on the verge" (SL 97). Moreover, there is continued emphasis on the fact that "[th] ere was a wall in him that no one reached" (SL 71), "a terrible horizon in him beyond which he couldn't leap" (SL 157). Like Anil, Patrick is separated from others by a boundary which he cannot cross. His disconnectedness from others is clearly not a "cunning device to conceal his potential for transformation" (Werth 129) but it shows a genuine inability to connect.

When he attempts to overcome this barrier that separates him from others, he uses non-verbal ways of communication instead of speech, but also does not mind his "lack of language" (SL 133). However, this is not because it "precludes [him of] any necessity to reveal himself" as Overbye claims (6), but it rather reflects the only other community he was ever part of before, namely his family whose way of communicating is marked by lack of conversation (Schumacher 5; cf. SL 10). It is only logical then that he does not feel uncomfortable when he is part of a nonspeaking community again. His silence and anonymity very soon make Patrick feel no longer "deliriously anonymous" (SL 112), though, but "utterly alone" when the Macedonians and Finns talk in their own language around him so that he is excluded (SL 115). Therefore Rod Schumacher rightly concludes that "[a]ny feelings of alienation Patrick experiences, either in the wilderness or in Toronto, arise not from some calculated withdrawal from the world, but rather from his inability to use language effectively" (4-5). In order to actually be able to use his theoretically greater agency he would thus just like the immigrants have to learn to use language.

Yet, this does not equalize their situations because unlike the immigrants Patrick does not know how to make the necessary changes and adjustments. $\mathrm{He}$ 
needs to rely on others to make him feel connected. He admits that within him there was "[s]omething hollow, so when alone, when not aligned with another whether it was Ambrose or Clara or Alice - he could hear the rattle within that suggested a space between him and community" (SL 157). While Alice thinks that he can be solitary because he is "self-sufficient" (SL 123), this self-sufficiency clearly is not of much use to him since there are things he is unable to do such as overcoming his sense of displacement that resulted from his (im)migration.

Temelcoff, on the contrary, is well prepared for establishing new connections in Canada, which is not surprising since he is part of a transnational network that helps him deal with the problems of immigration. Thus Temelcoff met others who have migrated even before he left Macedonia and knows that there will be people from his village in Toronto who he can go to for help (SL 46). These, of course, can provide advice since they have been through the same experience. Accordingly, Temelcoff is fully aware of what is needed to be successful and, for example, knows that "[i]f he did not learn the language he would be lost" (SL 46) and quickly finds work in several Macedonian bakeries because of his connections. Patrick, on the other hand, is utterly alone.

This extreme difference between the two characters is illustrated in the novel's use of light and darkness. Raphaël Ingelbien shows that light and darkness in In the Skin of a Lion function as metaphors of which light is connected with consciousness and empowerment whereas darkness stands for powerlessness and alienation (31-33). Temelcoff's transnational connectedness is therefore further highlighted by the description of him as someone who "came to this country like a torch on fire and he swallowed air as he walked forward and he gave out light. Energy poured through him" (SL 149). In addition, light in the novel is also often associated with naming, which in turn "is a necessary step in the process leading to social and cultural recognition" (Ingelbien 34-35). To be able to name something is to be able to identify oneself and others, thereby asserting one's selfunderstanding and also one's place in one's social location. Accordingly, if Temelcoff arrives "like a torch on fire" it indicates that he has already started his process of integration into the host country before his arrival. His social space thus is made up of a transnational network which provides assistance in his migration which then leads to his greater agency, mobility and flexibility and in turn to a higher chance of successful integration.

Patrick on the other hand is not part of such a network and instead lacks connectedness of any kind as shown above. This is strongly reflected in his migration experience which is not only not the same as Temelcoff's but in a way even more difficult. This is again reflected in the use of light and darkness. Contrary to Temelcoff, Patrick is frequently situated in utter darkness (SL 9, 105, 120, 166, 230) and as Ingelbien points out "mainly passive, looking for light without producing any" (34) which stresses his inability to make connections. The metaphor even goes to extremes in Patrick's case because he is not only in the dark, but also asso- 
ciated with blindness. For example, he is described as "a searcher gazing into the darkness of his own country, a blind man dressing the heroine" (SL 157). Hence, while his father once commented that the Finnish loggers of Patrick's childhood "don't know where they are" (SL 133; emphasis in original), Patrick realizes only through prolonged contact with the immigrant community in Toronto that they know more about his native country than he does (SL 157). Knowledge of their rich heritage additionally leads to his awareness that it is him who does not know where he is (Heble, "Putting Together" 241; Schumacher 13). He is further associated with blindness when he attempts to impress Clara by "blindfold[ed]" movement (SL 79), is "guided" by Hana through the immigrant quarter (139) like a blind man who needs to be lead and by his possession of a blind pet iguana (SL 83). All this clearly shows that Temelcoff is much better equipped to adjust to their new situation whereas Patrick is overwhelmed when faced with similar situations. Therefore, if Patrick's and Temelcoff's migrations are compared, Temelcoff's transnational connectedness allows him greater agency, whereas Patrick is unable to act because he has no network to help him. In a subversive move, the immigrant who is usually less advantaged is here portrayed as much better suited to life in a country that is continually changing through technological advances and immigration.

\subsubsection{Transformative Spaces}

In addition to their struggles with language and sight, Temelcoff and Patrick's movement towards transnational identities is also symbolized in the places and spaces they occupy in the narrative. Many critics have noticed that there are highly symbolic spaces in In the Skin of a Lion, which impact those who inhabit them immensely (e.g. Criglington 137-38; Lowry 63-64; Mason 78; Siemerling 97; Spearey 56; Stolar 132; Vauthier 76). The focus is often on the liminal character of such spaces, and an example very often used to demonstrate such a space in the novel is Union Station (Criglington 137-38; Lowry 63-64; Stolar 132).

Batia Stolar analyzes this in detail. When Patrick first comes to Toronto he watches an immigrant who seems caught in the space of the station. The man seems lost and unable to leave and when Patrick returns two days later, the immigrant is still there, "still unable to move from his safe zone, in a different suit, as if one step away was the quicksand of the new world" (SL 54). For this immigrant, "'home' [is] not in the immigrant communities but at - and in - the border" (Stolar 132) which "offers what no other place in the city can: a meeting point between these two extremes", that is between inside and outside (Stolar 132). This makes Union Station a literal description of Bhabha's third space. It is a space that is neither here nor there but in-between, a boundary from which something new can be created. And as correspondingly, "[s]omewhat paradoxically, the immi- 
grant, like Union Station itself, is simultaneously static and mobile, inside yet outside the city" (Stolar 132) he ought also be able to create something new.

However, the liminal space of Union station is also clearly very constrictive because even though the immigrant in theory is both inside and outside, he is in reality neither as a station is usually a transitional space and not a space to stay permanently. The passage emphasizes that there are real binaries and boundaries in the world which cannot be so easily hybridized. Accordingly, the immigrant is caught in a no man's land between stable points that is not hospitable at all. It isolates the immigrant, who has no connections, no belonging and no identity that can be attributed to him. As Stolar notes, "there is little that is known about [him]" and he is characterized by a "lack of specificity" (132). Inhabiting such a space can hardly be a positive experience because the immigrant is literally displaced from the world and, in addition, seems - probably as a result from his being in this place - rather mad, since he constantly shouts without addressing anyone: "The man's eyes burned through everyone who at first received his scream personally" (SL 54). Bhabha's notion of the third space which "gives rise to something different, something new" ("Third Space" 211) is undermined in this passage as the novel suggests that a permanent state of liminality is frightening and not desirable. The immigrant seems to blend into non-existence because he cannot be identified, cannot even identify himself and as a result is completely powerless and helpless.

This message is also emphasized in the liminal spaces Patrick and Temelcoff occupy. Thus, during the construction of the Bloor Street Viaduct, Temelcoff can be seen working not only on the bridge, but mostly below it, hanging suspended in "all that space" (SL 35) between the unfinished bridge and the river below, "lost to that community of men on the bridge" (SL 39). While Meredith Criglington comments that "the lyrical descriptions celebrat[e] the dignity, skill, and grace of Nicholas Temelcoff on the bridge" (139), the horror of his job is equally shown. One memorable description of his stepping over the edge "into the clean air" (SL 42) is located right next to a description of silent films in which a blindfolded Chaplin is about to step over the edge of a balcony and the narrator states, "These comedies are nightmares. The audience emits horrified laughter" (SL 43). The similarity of these two scenes and their close proximity to one another suggest a deliberate connection between them, especially considering previous instances of this ordering strategy, such as the use of cinnamon in Running in the Family. ${ }^{36}$ The narrator's comment on Chaplin must accordingly also be applied to Temelcoff. His disconnected state in the empty space under the bridge is not only literally dangerous but also symbolic in terms of his isolation and disconnection in the process of integrating into his new country.

36 See page 318 , note 34 . 
This space also has transformative effects in a metaphorical sense. It is a stage that has to be passed through to get somewhere else, to start a new life. Accordingly, the next time Temelcoff is mentioned in the narrative after the episode on the bridge, he is integrated into his new life in Toronto's immigrant community and is no longer the silent, unconnected immigrant mentioned in the previous chapter. Susan Spearey generalizes such spaces in In the Skin of a Lion and explains:

Ondaatje's vision of order is one of constant reformulation, one that depends on the diverse and multifarious range of individuals and communities in any given space, and one that involves the dialectical play of powers within and between the boundaries which divide these groups. In the process of such dialectical play, as in migration and metamorphosis, the disorientation caused by the shifting of parameters enables reorientation, reformulation. Existence in liminal areas in which contexts or frameworks of order become unclear allows for revision of such order. (56)

These liminal spaces thus change the "order" and "boundaries" they come in touch with as well as the people who inhabit them which is clearly reminiscent of the way transnational social spaces come into existence. After all, they are a result of the revision of what Vertovec calls the "identities-orders-borders" of nationstates ("Migrant Transnationalism" 158). Yet, it also shows the difference between transnational space and liminal space because permanently being in the latter will still lead to displacement and exile as in Bhabha's notion of liminality, which the example of the immigrant in union station suggests. As with Bhabha's third space, there is constant change and constant hybridization, which does not allow for stability that would make identification possible and would also preclude agency as the example of the immigrant in Union Station showed. Hence, this space also has to be left at some point since otherwise the "images of metamorphosis" (Spearey 48) which occur in it will never end and prevent connections to others as well as a somewhat coherent self-understanding. After all, for any kind of belonging and groupness, there needs to be commonality and connectedness. Commonality among people can hardly persist if a person never stops metamorphosing for even a moment. Liminality then becomes a space between a person and community that excludes the liminal subject from what surrounds the liminal space.

However, if this space is merely passed through, it leads to changes, "reformulation" and "revision" which for the migrant figures of the novel results in the formation of transnational social spaces and transnational identities that encompass the originals as well as change them. ${ }^{37}$ For the novel's characters, passing

37 Criglington (134), Winfried Siemerling (97) and Spearey (56) all mention the transformative effect the liminal space between bridge and river has on Alice who starts a new life after her fall from the bridge. None of them relates it to Temelcoff, though. Notably, her fall will also eventually result in the friendship with Temelcoff and thereby her introduction to the immigrant 
through liminal space is thus a period of adjustment, which allows them to change in such a way that they can connect to their new environment, which will, however, also be modified through these spaces. ${ }^{38}$

This is illustrated well in the character of Patrick. He, too, occupies transformative spaces repeatedly, of which I will only focus on two here, the Island of the Blind and Union Station. While the island may at first not seem like a particularly liminal space, it is nevertheless in an in-between location because on the one hand it is land, but on the other hand it is disconnected from the mainland and surrounded by water. Patrick's being on it illustrates his continuing lack of belonging. It echoes John Donne's "No man is an island, entire of itself; every man is a piece of the continent, a part of the main" (1305). Patrick, however, is depicted as such an island in his disconnection from all community. Unlike Temelcoff, Patrick unsurprisingly has to pass through several transformative spaces until he finally changes and becomes able to connect to his surroundings. The scene of the Island of the Blind is very evocative in this respect, because it highlights the theme of blindness usually associated with Patrick. On the island he is able to see, but lacks other senses that are needed there and relies on a blind woman he meets on the island to guide him through it (SL 168-71). He is thereby still separate from the community surrounding him in this space. As a result, this transformative space cannot change Patrick either: the woman symbolically blinds him before he leaves by covering his eyes with her hands (SL 170) so that Patrick is not transformed but returns to the mainland still unable to see.

His transformation finally takes place almost at the end of the storyline when he returns from prison and passes through Union Station, in a passage which is charged with allusions to all the things that kept him from connecting throughout:

A group of redcaps were standing with three large cages full of dogs, all of whom were barking like aristocrats claiming to be wrongly imprisoned. [Patrick] went up to the cages. They were anxious with noise. He had come from a place where a tin cup against a cell wall was the sole form of protest. He got closer to the cages, looked into the eyes which saw nothing, the way his own face in prison had looked in a metal mirror.

He was still crouched when the redcaps wheeled the cages down the ramp. On his knees in Union Station. He felt like the weight on the end of a plumb-bob hanging from the very centre of the grand rotunda, the absolute

community and its transnational space. It is likely also the moment of Temelcoff's transformation because "he sees the landscape as something altered" after that night (SL 48).

38 Regarding this, Sergio Perosa offers an interesting analysis of how the immigrants' work at "linking devices" (185) such as the bridge leads to changes in the structure of the city and turns it into a space that is "suited for new nomads, internal as well as external nomads, rather than settlers" and makes Toronto a place of "interchange and integration" (186). It symbolizes how the influence of liminal, transformative spaces can affect its surroundings. 
focus of the building. Slowly his vision began to swing. He turned his head to the left to the right to the left, discovering the horizon. (SL 210).

In this moment Patrick becomes aware of everything that has separated him from others all along. His silence is contrasted with the noise of the dogs and he sees his blindness reflected in their eyes. He now begins to see and recognizes the horizon, which clearly evokes the "terrible horizon in him beyond which he couldn't leap" (SL 157) but is now able to. With the beginning of the following paragraph "[h] moved tentatively into the city" thereby crossing the "horizon" and once he arrives in Temelcoff's bakery, Temelcoff greets him with "[t]he grip of the world" (SL 210) so that Patrick, too, has finally reached a state of connectedness.

\subsubsection{Narrating the Self}

Another last step is needed for both characters to finally develop transnational identities: the awareness of their multiple connections and affiliations which will lead to a change in their self-understanding. This last change occurs through the use of narrative through which Patrick and Temelcoff will narrate their transnational selves. In the scene that gave the novel its title, Alice tells Patrick of a play in which a number of actresses took turns playing the central character. To demonstrate whose turn it was, they passed around a storyteller's coat decorated with skins. The narrator comments, "Each person had their moment when they assumed the skins of wild animals, when they took responsibility for the story" (SL 157). Speaking and telling stories is thus a sign of power and agency and taking up the skin and narrating a story is a symbolic act to identify as the hero of the play. A similar act also occurs in both Temelcoff and Patrick's final deliberate identification with their transnational identities and ways of life. After all, the act of publicly speaking and telling one's story equates to identification with it and shows a character's self-understanding which in Patrick and Temelcoff's case is made up of references from multiple places and cultures. By telling their stories these two will then identify with their transnational selves.

So far, both Patrick and Temelcoff have found ways to connect to their new environments and are both equally part of a transnational social field: Patrick, the native Canadian, is integrated into the immigrant community and Temelcoff, the immigrant, in addition also is "a citizen here, in the present, successful with his own bakery" (SL 149). However, both characters are only engaged in ways of being without emphasizing their transnational belonging. The text stresses that "Nicholas Temelcoff never looks back. He will drive the bakery van over the bridge with his wife and children and only casually mention his work there" (SL 149). Criglington therefore assumes that " $[\mathrm{w}] \mathrm{ith}$ his immigrant's desire to integrate, Nicholas has repressed his old identity" (135). He has hardly suppressed it, though, since he still lives in the immigrant part of town and accordingly still is 
part of that community (SL 210). Nevertheless, he does not seem to highlight his connections very much because he is too busy forging new belongings to pay much attention to the old ones. As he says, "That was all he had time for in those years. Language, customs, family, salaries" (SL 149). Nonetheless he is still located in transnational space, which is cleverly depicted in his use of and history with the bridge. Criglington thus points out, "Nicholas Temelcoff, the focal character in 'The Bridge' chapter, personifies the bridging metaphor" (134). He can literally be seen to link and travel back and forth between two worlds. Yet, by not emphasizing this he is only engaged in ways of being a part of transnational space.

However, Temelcoff changes during the course of the novel and eventually develops ways of belonging, and he does so through narrative. This change is induced by Patrick who finds out that Temelcoff worked on the bridge and confronts him with his past thereby giving Temelcoff a "gift" which for him is an "arrow into the past, [that] shows him the wealth in himself, how he has been sewn into history. Now he will begin to tell stories" (SL 149; see also Criglington 135). In taking up the narrative, Temelcoff then begins to tell the story of his 'self', and reinforces his transnational self-understanding in the process. He thereby changes from merely being transnational to transnational ways of belonging since taking up the narrative is also a statement that identifies him with his past and his Macedonian heritage.

Similarly, Patrick's being part of the immigrant community is at first merely a matter of being but turns into ways of belonging also, which nevertheless has its setbacks and takes much longer than Temelcoff's. Criglington states that "Patrick is adopted by the immigrant community in Toronto's east end, and he in turn takes charge of Hana as his adoptive daughter" (147), the symbolic value of which is even further emphasized by Branko Gorjups' fitting assessment of Hana as "the symbolic daughter of the entire community" (94). Even though adopting Hana is a significant statement that aligns Patrick with his new 'country' of the immigrant community in ways of belonging, he cannot entirely belong to it until he is able to articulate it through language. Accordingly, there is a doubleness to his adoption of Hana, which is linked to his use of language. He at first tells Alice that he wants to "look after Hana [...]. More formally" (SL 158) but eventually cannot accomplish what is necessary by this quasi adoption of the girl. Ingelbien shows that after Alice's death Patrick relapses into silence as symbolized in his return to darkness (35; see also Schumacher 15). Patrick clearly has not yet learned to produce light of his own and relies on others to connect him to a community.

Accordingly, he cannot take up the responsibility for either his story or Hana's because he has not yet discovered a voice of his own. Strikingly, he leaves Hana with Temelcoff when he goes off to burn down the Muskoka hotel, knowing full well that he will probably be caught and imprisoned so that he will be unable to fulfil his responsibility as her father (SL 211). Only when he manages to find a voice and pass the space between him and community at the end of the novel, is 
he finally able to announce to Clara "I am her father" (SL 218) which formalizes the adoption of both Patrick and Hana. It is also at this point that he takes up the lion's skin and becomes a story teller who on their journey to Marmora tells her the story that is contained in the novel as the frame indicates: "This is a story that a young girl gathers in a car during the early hours of the morning" (SL 1; emphasis in original). It is a story that locates Patrick in the immigrant community and as well introduces Hana to her heritage (Criglington 132; Gorjup 94; Overbye 12). It also altogether emphasizes the transnational lives of father and daughter by highlighting their various affiliations and belongings and the fusion of different nationalities in their family.

In addition to this, Stolar points out that telling Hana the story of her community also turns Patrick into a "spokesperson" for the immigrants (128). She further states, "The political force of the revolutionary immigrant is thus transferred to the English voice that has been naturalized an immigrant voice by virtue of his choice of urban residence and employment" (128). She fails to see that Patrick is only able to use his "English voice" because he has finally learned to use language effectively. Yet, the story of his learning the language doubles back to the immigrants because Patrick begins to learn to use language through Alice when she introduces him into the community. Alice's connection to the immigrant community, however, in turn started by the bond formed between her and Temelcoff on the night she fell from the bridge when she became his "twin" (SL 49). Patrick would not be able to be the person he is at the end of the novel had it not been for the influence of the immigrant community in his life. Patrick's becoming a representative of the immigrant community thus becomes another instance in which "the whole idea of socio-cultural centrality is undermined" in the novel (Vauthier 72) since the Canadian protagonist of the novel is only able to act when he is no longer purely Canadian. There is hence no longer just one dominant homogeneous national culture, which dictates the behaviour of minorities and forces them to assimilate to its order but the immigrant minorities can be seen to change their host country from within and to be much better suited to living in such heterogeneous nations (see also Werth 127). Accordingly, the national space of In the Skin of a Lion's Canada becomes a transnational space in which the formation of transnational identities is possible.

\subsection{The English Patient: Transnational Dreams}

The English Patient just as In the Skin of a Lion makes abundant use of symbolic spaces to depict its characters' identities while also applying the fusion of boundaries characteristic of Anil's Ghost and Running in the Family. As Ondaatje's most famous and therefore most thoroughly researched novel, there are a plethora of different opinions concerning its stance towards the interplay between nations and 
identities. For example, while some comment that it undermines the idea of nation-states' power as a source of identity (Burcar 99; Papayanis 223), others emphasize how it provides an image of life in a postnational world (Delbaere 49; Ibarrola-Armendariz 41; Kella 92). Others again claim that the latter is then destroyed by the continuing power of imperial nation-states in a reaffirmation of nation-states' power (Burcar 109; Goldman 190). Consequently, it is also argued that the novel eventually negates the idea of identities that cut across national boundaries and reasserts national belonging (Kemp 151; Turcotte 70). A thorough analysis of its use of spaces and its dissolution of boundaries will reveal quite different results. These are emphasized by a comparison of Kip and the English patient who are the novel's two central migrant figures and who are much more different than they initially appear. Through this the novel also comments on transnational identities and ways of life and the chances of their survival in a world dominated by nation-states.

\subsubsection{Two Transnational Spaces: the Villa and the Desert}

Two transnational spaces figure prominently in the novel: the Italian villa community, made up of Hana, Kip, Caravaggio and the English patient, and the African desert explorers' community which the patient recalls in his memory. Both groups constantly negotiate questions of nationality and belonging which as in In the Skin of a Lion are expressed through the relationship between its characters and the spaces they inhabit. The community in the desert and in the villa seem models for transnational connectedness at first. The characters in the villa coexist peacefully without negating their cultural and national differences (see also Younis, "Race" 55-56). They are thus not separated from their past as Jeanne Delbaere claims (49) and have not "shed the clothing of their countries" either (Papayanis 235) but on the contrary still feel strongly connected to the places they left behind. Hana frankly states her affiliation with "Upper America" (The English Patient 81) (39 $^{2}$ and is clearly very attached to Canada for which she feels homesick (EP 135). Kip similarly freely admits to his Indian heritage (EP 81) and, for example, continues to wear his turban, which connects him to his religion and through it to his home in India (EP 79). All of them share the common experience of migration and are equally scarred by the war in which they all were involved and can thus relate to one another despite being of different nationalities.

Yet, they do not only tolerate each other's differences, they also actively attempt to transcend national and cultural affiliations by collapsing the boundaries between their countries. Hana wishes she could take Kip to Canada to show him her world there (EP 137) and, "[d]uring the verbal nights, they travel his country

39 Henceforth EP. 
of five rivers" (EP 288) together, Kip not only envisions but narrates into existence a life for him and Hana in India:

He guides her into the great gurdwara, removing her shoes, watching as she washes her feet, covers her head. What they enter was built in 1601, desecrated in 1757 and built again immediately. In 1830 gold and marble were applied. 'If I took you before morning you would see first of all the mist over the water. Then it lifts to reveal the temple in light. You will already be hearing the hymns of the saints - Ramananda, Nanak and Kabir. Singing is at the centre of worship. You hear the song, you smell the fruit from the temple gardes - pomegranates, oranges. The temple is a haven in the flux of life, accessible to all. It is the ship that crossed the ocean of ignorance.'

They move through the night, they move through the silver door to the shrine where the Holy Book lies under a canopy of brocades. The ragis sing the Book's verses accompanied by musicians. [...] Kip walks her beside a pool to the tree shrine where Baba Gujhaji, the first priest of the temple, is buried. (EP 288)

Kip's description of his India collapses all boundaries of distance and time. It is not an imagined future, which he and Hana could one day share, but it is a space they inhabit immediately as the use of the present tense indicates. Kips "guides her" and watches "as she washes her feet", and while his account of the river and the singing is at first something she "would" hypothetically hear, it soon switches to a present that seems to envelop Hana as well who can also "hear the song" and "smell the fruit". Together they "move" through a place, which is geographically far away but simultaneously present for them in Italy, "in [Kip's] tent, in 1945, where their continents met in a hill town" (EP 239). It is a perfect symbolic representation of a transnational social space which is at the same time both here and there. Caravaggio and the English patient are likewise equally enamoured with this idea of connectivity since Caravaggio wishes for Kip and Hana to be married (EP 284) and the patient sees in Kip a fellow "international bastard" who lives independent of national boundaries (EP 188).

Instances of simultaneity and fusion of spaces abound throughout the description of the villa and additionally reflect this theme. Like its inhabitants it is "in near ruins" (EP 29). There are holes in its walls (EP 12) and some walls are altogether missing (EP 14). Nevertheless, the house "had adapted itself to this wound, accepting the habits of weather, evening stars, the sound of birds" (EP 12). The boundary between inside and outside has thus become blurred and the villa seems to encompass both at the same time. It is as if the trompe l'oeil that covers the patient's room (EP 33) has become real in the space of the opened up villa as its walls have become "interchangeable with living gardens" (Papayanis 235). Kip's tent in the villa's garden likewise presents a fusion of spaces since it is both a mere tent and also almost a part of Kip's body, "a khaki wing he folds over himself 
during the night" (EP 135). It is his "world" (EP 135), and as Elizabeth Kella observes (100), Kip even symbolically sleeps half inside, half outside his tent (EP 81) which locates him simultaneously in his private world in the tent and the world surrounding it.

Similarly, the desert is another "in-between space $[\ldots]$ where the concept of national enclosures and imperial boundaries collapses" (Burcar 103). The patient explains that "it is easy to lose a sense of demarcation" there (EP 20) because "nothing was strapped down or permanent, everything drifted" (24). The desert, too, is a "trompe l'oeil", both real and at the same time a painting of "time and water" (EP 257) which makes it possible for the community of desert explorers to reconcile irreconcilable differences there. Thus they can be in the oxymoronic state of being "desert European[s]" (EP 260), simultaneously belonging to both the desert and Europe. Like the inhabitants of the villa they can likewise be "planetary strangers" (EP 259; see also EP 49): different but nevertheless connected in the same "system" (EP 79). Both communities are therefore connected by a sense of transnational groupness.

However, for all its emphasis on connectedness, the novel from the start points out the inevitable destruction of these two transnational spaces, which is foreshadowed long before the war and the dropping of the atomic bombs. The atmosphere in both the desert and the villa constantly stresses the illusionary nature of both spaces. At times they appear like the magical landscape of fairy tales in which - in the case of the villa - characters from books come alive as when Kim's entrance into the villa community seems to Hana as if he has stepped out of Kipling's Kim (EP 117) after "those long nights of reading and listening" (EP 118). The patient's "talk[ing] in his circuitous way" (EP 95) in addition portrays him as a storyteller who imagines stories such as "the half-invented world of the desert" (EP 160). It is made clear that he does not care about "the outside world" (EP 152), namely reality, which is especially apparent in the patient's description of the desert.

The patient's desert is an otherworldly, mystic place filled with eclipses and the "half-darkness of the covered sun" in which power is drawn "into his body from the universe" while he is surrounded by the eerie sounds of "wind chimes" (EP 9) and clinking glass bottles through which one can see "translated light - blues and other colours shivering in the haze and sand" (EP 10). At times he is not even sure if this is dream or reality (EP 24). ${ }^{40}$ In any case, both places seem more like fantasy structures than reality and bear little resemblance to their real counterparts which is unsurprisingly emphasized by descriptions of the villa as a "miniature world" (EP 49) which just as the desert community is separated from the outside world (EP 42; 118; 156). These places appear to exist in and of themselves, com-

40 One could argue that the patient is at this stage somewhat delusional because of the burns he suffered in the plane crash but his obsession with the dream-like, invented character of the desert can be found even before that. See for example EP 261-62. 
pletely cut off from the world that surrounds them. However, if they are not part of the real world they cannot really be transnational spaces, which would require an overlap of spaces that cannot take place if their boundaries/separateness are insisted upon. There is a logical breach at the centre of both transnational spaces and communities which reveals all transnational connectedness to be only a dream, which like the patient's trompe l'oeil only seems true in moonlight (EP 33).

This leaves an apparent paradox since on the one hand the desert and the villa clearly are described as transnational spaces but on the other hand they are characterized in a way that makes their existence impossible. The narrative perspective of these passages clears up the confusion. Hence, the emphasis on the villa's separateness from all other communities is mainly voiced from Hana's perspective or a description of Hana's behaviour. She is the one who feels "secure in the miniature world she had built" (EP 49; my emphasis) and not unlike her father, Patrick Lewis, she is characterized by a certain degree of blindness. She can be seen "closing her eyes against the world around her" because she cannot take the trauma in the war hospitals around her any longer (EP 51). Furthermore, her obsession with the English patient further stresses her desire to escape reality. She wants to "throws herself out of the world to love a ghost" (EP 47) because "[t]here was something about him she wanted to learn, grow into, and hide in" (EP 54). That she has succeeded in this wish becomes apparent in her way of talking about the villa. By describing it as a world of its own, she likens it to the patient's description of the desert and thereby admits that she has taken up his perspective of these transnational spaces. This is completely at odds with the model of transnational connectedness Kip expresses as shown above. This clash introduces a destructive potential into the space of the villa. It can best be seen in the patient's and Kip's approaches to cross-national situations which, upon closer inspection, are radically different from each other.

\subsubsection{Kip and the Patient as Contrasting Migrant Figures}

The English patient and Kip at first seem to be very similar characters since both are migrants whose lives span several countries. Kip with his Indian background does not only identify with India as seen above but also with England because in colonial India he was brought up with traditions from both countries (EP 301) and during his time in England he started "to love the English" (EP 202). Likewise, the patient appears to be connected to several cultures and nations. In addition to English, he can speak German and appears as equally familiar with the cultures of England and the rest of Europe (EP 101) as with the tribes of the North African desert (EP 144). As Rufus Cook sums it up, "So extensive is his learning that he seems to transcend time, place, and ethnic origin; he feels equally at home among the English, the Bedouin, and the ancient Greeks or Egyptians" 
(45). However, he claims to have forgotten his nationality because of his accident (EP 6) and consequently cannot be named or identified (EP 102).

The patient nevertheless stresses the similarities between himself and Kip, and there are certainly many. In addition to their shared migrant background, they are both equally self-sufficient (EP 134, 252), they value their independence above all (EP 135, 253) and are defined by the skill of their respective professions (EP 116, 255). Kip is furthermore enthralled by the patient's encyclopaedic knowledge which leads to their frequent discussions of a diverse range of topics, for example the defusing of bombs (EP 95). Because of this Kip is repeatedly found sitting on the patient's bed, which leads the latter to liken this scene to a painting by Caravaggio, David with the Head of Goliath. The painting shows David gazing at the face of Goliath, in which David's face is supposedly modelled after the young Caravaggio and Goliath has the face of Caravaggio in his old age. The patient concludes, "Kip is my David" (EP 123) and sees his younger self reflected in the sapper (see also Kella 109), thereby stressing the similarities he sees between them.

Nevertheless, there are also striking differences between them which the patient and Kip, too, initially fail to see. Kip clearly attempts to lead a transnational life, which can be discerned in the description of his time in England. After initial difficulties and alienation (EP 199), he joins Suffolk's team and "stepped into a family, after a year abroad, as if he were the prodigal returned, offered a chair at the table, embraced with conversations" (EP 201-2). Even though other English people do not recognize him as an equal and categorize him as 'other', thereby stressing that for them he does not belong to their nation (EP 209, 225), the relationship with Suffolk and his group is marked by respect and acceptance. Markedly, throughout the chapter "In Situ" which recounts his experiences in England, he is not called 'Kip' as in the rest of the novel, but by his real name 'Singh' which consequently highlights his Indianness but does not thereby distance him from the English around him. ${ }^{41}$ On the contrary, this is the chapter in his life in which he is most accepted into English society and actually feels he belongs there as part of Suffolk's family. ${ }^{42}$ After Suffolk's death and Kip's departure from England his identification with the country does not change: "Kirpal Singh had been befriended, and he would never forget it" (EP 199). Nonetheless he is always aware

41 Towards the end of the chapter, Miss Morden calls him Kip once (EP 215) but as was stated before, "Lord Suffolk and his demolition team took to calling him by his nickname, which he preferred to the English habit of calling people by their surname" (EP 94). The narrator's usage of Kip's real name clearly emphasizes a different, more accepting attitude towards Kip's difference without attempting to familiarize him by "translat[ing] [him] into a salty English fish" (EP 93-94). Likewise, he is also referred to as Kirpal Singh a few times towards the novel's end after he has rejected any idea of transnational belonging and has re-established his national identity (EP 305, 307).

42 The emphasis on the respect for Kip's difference expressed through the use of his real name is strikingly absent in the transnational space of the villa. 
of his "invisibility" to most English people which results in the self-sufficiency he shares with the English patient (EP 209).

His desire to affiliate with England does not solely stem from his friendship with Suffolk, though. As Younis explains he began to "love the English at an early stage" and does not view them merely as colonizers even though his family is negatively affected by the colonization of India ("Nationhood" 5). After all, his brother is in jail as a consequence of his anti-colonial resistance (EP 287-88). Nevertheless, Kip "seems to have a more fluid sense of the relation between nation and identity [and] seems to reject the stark binarism that characterizes a number of accounts of the relationship between colonial expansion and post-colonial affirmations of independence" (Younis, "Nationhood" 5). Thus, he defends his choice to fight in an English war even though he is Asian and Asia is colonized by the English. For Kip loyalties are a much more differentiated matter: "Japan is part of Asia, I say, and the Sikhs have been brutalized by the Japanese in Malaya. But my brother ignores that" (EP 230). He defiantly struggles to defend his transnational self-understanding, even if it means that he has to disagree with his family.

The patient on the contrary may have forgotten his nationality but he certainly has not forgotten his hatred of the very concept of nations. During his time in the desert he develops a strong desire to "Erase the family name! Erase nations!" by which he claims people are deformed (EP 148). As a consequence he reconfigures the formerly transnational space of the desert into a postnational "pure zone" (EP 262) devoid of all markers of nationality and belonging. He states:

The desert could not be claimed or owned - it was a piece of cloth carried by winds, never held down by stones, and given a hundred shifting names long before Canterbury existed, long before battles and treaties quilted Europe and the East. Its caravans, those strange rambling feasts and cultures, left nothing behind, not an ember. All of us, even those with European homes and children in the distance, wished to remove the clothing of our countries. It was a place of faith. We disappeared into landscape. Fire and sand. (EP 147-148)

This is the place in which, according to the patient, the former desert Europeans become "their best selves" (EP 262), which are "nationless" (EP 147) and their "own invention[s]" (EP 262). The postnational idyll lined out here, however, must be considered very critically because by turning the desert into a postnational space, the patient denies the existence of the histories and cultures of its inhabitants who, according to him, "left nothing behind". His behaviour has consequently been described as "arrogantly Eurocentric" (Kemp 143) and "a form of grotesque narcissism" (Shin 218). In addition, the patient refuses to notice that not everyone shares his naive view of the desert and that his charting of it will inevitably be used for imperial pursuits, which makes him responsible for its destruction (Papayanis 223). The ones who attempt to be postnational are as a result 
portrayed as being able to cause just as much harm as those with a nationalist agenda. The patient's postnational dreams clearly fail to grasp that even if he tries to disassociate himself from nationality, nation-states nonetheless possess great power which must be reckoned with.

Nevertheless, the patient's view of an idyllic nationless world is "seductive" (Goldman 185) and both Hana and Kip fall under its spell. As shown above, Hana subscribes to the patient's idea of communities which are separated from the world and in sharing his dream of postnationality becomes his "true heir" (Papyanis 236). Kip comes to regard him as a father figure: he "believed in the burned man and the meadows of civilisation he tended" (EP 313). This makes it easy for postnational thoughts to slip into the villa community and erode its transnational potential just as the community in the desert was destroyed. Through this, the text makes an adamant statement that hiding from the world and effacing differences is not an answer to the question of how to reconcile national differences. This is also distinctly represented in the character of the patient. As Cook remarks, the patient is the "most thoroughly negated or nullified character in the novel" and turns into "a synonym for absence or anonymity" (R. Cook 46). This is not a result of his absorbing too many cultures (R. Cook 46), though, but on the contrary a result of his rejection of all affiliations and connections. Even the patient understands this towards the end: "He is exhausted not from the desert but from solitude" (EP 187). To be postnational then is to be isolated and reduced to nothingness. Thus the patient's postnational dream ultimately is dismissed as a dangerous delusion (see also Smyrl 15).

Kip's painful recognition of this is symbolized in his final scene with the patient. After he heard of the dropping of the atomic bombs on Asia he confronts the patient in a manner which resembles their previous conversations and thus their pairing as David and Caravaggio. However, this time he points his rifle at him and watches him through it, undecided as to whether he should shoot him (EP 302-3). In a reversal of the former scene it is now Goliath who shows David his future, which is filled with death as the burned patient clearly resembles the dead in Hiroshima and Nagasaki (see also Kella 109-10). Postnational behaviour is thus portrayed as inevitably resulting in destruction. In addition, Kip's accusation that the bombs would never have been dropped on a white nation (EP 304) furthermore emphasizes that even transnational belonging is not possible for Kip because, as before, he would not be accepted in England as a colonial and nonwhite person. He will always be identified and categorized as the other who does not belong there. As Delbaere points out, the scene emphasizes "the precariousness of human efforts to do away with the carcans of nations and races and to rechart the world in terms of a global community" (55). At this point in the novel, both transnational and postnational identities are rendered impossible. 


\subsubsection{Transnational Illusions?}

So far, the novel offers a grim perspective on the formation of transnational identities. The promising initial transnational connections in the novel have turned out to be illusions. Any trace of transnational sentiments that had been left in Kip immediately disappears upon his hearing of the news of the atomic bombs. He is "separate from the world" (EP 301) in the patient's room, which is "crowded now with the world" (EP 303). The two worlds mentioned here clearly stand for two very different things. Kip is exiled from one of these worlds, the villa community, and arrives in the other, in his real world again which is dominated by conflict between nations and cultures. Brutally confronted with real life he can no longer remain part of the postnational villa community and realizes that any connectedness on his part to a Western nation will ultimately be denied so that he must leave. In fact, he seems already partly gone while he still occupies the villa's space, which is conveyed by frequent references to Kip's body surrounding the immediate news of the bomb. Hana remembers the "line of movement Kip's body followed out of her life", she hears "a scream emerge from his body" (EP 300) and can see that "his brown face is weeping" (EP 301). The Kip who travelled with her to India in his mind is no longer there, though. He seems split, his mind and personality already elsewhere while only his body remains.

This is further emphasized by his reassertion of a purely Indian identity. He can no longer be connected to several nations and realizes that he is no longer Kip but "Kirpal Singh and he does not know what he is doing here" (EP 305). As a consequence, he rejects his British uniform in favour of traditional Indian clothes (EP 305) and finally leaves. The breach seems irrevocable as his return journey indicates that he can no longer occupy transnational spaces. Having been fascinated with churches and Christian art throughout the novel, he can now no longer enter the church he wants to revisit, "unable to enter the intimacy of a home" (EP 310). Thus the community is disbanded: Kip has left, the patient dies and with him his postnational ideals, and Caravaggio and Hana return to Canada. It seems as if the possibility of transnationality has only been an illusion (see also Kella 102).

It is important to note that the novel does not end like that. Delbaere stresses that an attempt at some reconciliation is already made through the novel's use of intertextuality during Kip's journey home. Riding on his motorcycle he cannot shake off the image of the patient who seems to sit in front of him and sings Isaiah to him. She explains, "[t] he words that 'shall not depart out of [Kip's] mouth' (p. 294) are those of Isaiah who, as we know, prophesied the recovery of the garden in which the wolf would dwell with the lamb and the leopard with the kid" (Delbaere 55-56; emphasis in original). There is still hope that differences can be reconciled which is further affirmed in the unbroken connection between Hana and Kip (see also Papayanis 237). Younis sums up the novel's sentiment precisely: 
[T]wo nations, two nationalities, meet and the space of the intersection is transformed, for the result is memorable and affirmative. The implication is touching and unexpected: despite the evolution of their lives as individuals and family persons, the things that they shared have a quiet and sustaining vitality and an undiminished, secret life that bridges worlds, countries, and modes of being.

The novel suggests ultimately that Kip and Hana are not alone; that the secret connection between them is irrevocable. In this way, the novel's end suggests, once again, to be sure, that it is the things that bring two nationalities or two people together, and not the things that separate them, that are ultimately of the greatest value. ("Nationhood" 7)

A new transnational space is created which allows Hana and Kip to again collapse space and time as during their time in Italy and this space is so strong that it is almost possible to physically connect across the boundaries of Hana and Kip's nation-states as symbolized through Kip's catching the glass Hana drops in Canada as well as his daughter's fork in India (EP 321). Thus, transnationalism is not ultimately rejected in the novel but tentatively but nevertheless hopefully reaffirmed. The transnational space that was opened up in the villa community was not an illusion, but a dream of a future in which transnational identities become possible. It seems to echo the ending of Forster's A Passage to India. As with the friendship between Aziz and Fielding, the message for Kip and Hana's younger selves is "No, not yet,' [...] 'No, not there." (Forster 288). However, it is not Kip who connects with Hana in this passage but Kirpal (EP 321) and as the use of Kip's real name emphasizes, only when both parties have equal rights and there is no attempt to level out the differences between them can there be a connectedness that will not discriminate against one of them. The novel therefore distinctly rejects a postnational view of the world but on its last pages returns to the vision of transnational identities from the start, yet under more hopeful auspices.

\subsection{Divisadero: Piecing Together Imagined Worlds}

With Divisadero, the theme of transnational identities and the spaces in which they exist at first glance appears to have come to an abrupt halt. Even the usual focus on connectivity that figured so prominently in Ondaatje's previous fiction appears to be missing. The narrative diverges and splits into two seemingly very different, unconnected narrative strands: the novel's first part is concerned with the lives of Anna, Claire and Coop in California, their traumatic separation after Anna's father tried to kill Coop, her boyfriend, Claire and Coop's eventual reunion and Anna's moving to France to investigate the life of the fictional writer Lucien Segura. The second and third parts leave this storyline altogether - except for a few brief 
glimpses of Anna's life in France - and focus on the life of Lucien Segura. Subjectwise, this latest of Ondaatje's novels is not as expressly concerned with the formation of transnational identities as the texts previously analyzed. Yet, I am going to read it as an outlook on the further development of these issues in Ondaatje's fiction. Reviewers have called Divisadero "oblique, glancing and frustratingly inconclusive" (Parker) and "a more stubbornly eclectic Ondaatje book than most" (Maslin). Taken at face value it certainly is but a more thorough analysis reveals such astonishing parallels that Divisadero might well be seen as a dissolution of boundaries taken to extremes.

\subsubsection{Anna's Journey}

While Divisadero seems radically different from Ondaatje's other novels, this latest book shares a common motif with the previous ones: a journey. As shown above, journeys in the other texts, however, are not only literal journeys of the characters but contain an additional deeper, symbolic meaning. Considering this, Anna's travelling to France deserves special attention since in Ondaatje's fiction a journey never appears to express a mere change in location. Unusually, on the surface Anna's voyage does not offer much in terms of the transnational connectedness or any connectedness for that matter - which figures so prominently in the other books I have analyzed. Even though the novel's protagonist travels to another country, her journey is just that: a journey. As she says, she "came to France [...] to research the life and the work of Lucien Segura" (Divisadero 135) ${ }^{43}$ which does not convey an intent to stay permanently. On the contrary, she makes it clear that this is not "her real world" (D 66). Yet, it is hard to say what Anna's real world is if one considers her life up to the point of her arrival in France. In terms of plot, she got estranged from her family, ran away, studied French at university ( $D$ 89) and eventually became a professor of French Literature ( $D$ 88). Home or belonging are accordingly difficult to define for her.

Interestingly, from the beginning Anna does not only surround herself by everything French but also uses it as an escape from real life. Thus she pretends to be a "French girl" on her flight from home (D 144) by not speaking English to the man who gives her a lift in his car $(D$ 147). While this could be explained as a mere attempt to advert unwanted conversation, the influence of French culture on her life becomes more substantial later on. As her constant references to French literature show, she clearly sees her life reflected through these books. For example, she compares her Californian history to Balzac (D 13), a practice which she continues during her stay in France, likening the landscape of Europe to Stendhal ( $D$ 77). Fiction seems to be part of her reality and as present as the landscape sur-

43 From now on abbreviated as $D$. 
rounding her which already represents an instance of if not dissolution, then certainly a weakening of the boundaries between reality and fiction.

This is especially striking since Anna also speaks of her belief that "we live permanently in the recurrence of our own stories, whatever story we tell" (D 136). Considering that she is a writer who presently works on researching the story of Lucien Segura's life, this comment certainly suggests a deeper meaning: what if she does exactly this with Lucien's life? This suspicion is further supported by several of her remarks that she enjoys "hid[ing] in a stranger's landscape" (D 75) in order to escape the violence of her past. It appears that she does exactly this while living in Segura's house in France.

Her mentioning of the "small fictional street" Hugo supposedly created for the fictional character "Jean Valjean to slip into, in which to hide from pursuers" ( $D$ 142) mirrors her behaviour. While this could be merely another instance of the abundance of references to French literature that line her narrative, her following mentioning of the street she lives on in San Francisco nevertheless introduces another element of doubt concerning the truthfulness of her story. One cannot help but wonder whether she really lives on Divisadero Street or if this is her fictional street. It would be convenient indeed if she lived on a street named after "the Spanish word for 'division,' the street that at one time was the dividing line between San Francisco and the fields of the Presidio. Or it might derive from the word divisar, meaning "to gaze at something from a distance" (D 142). Especially since she further comments: "It is what I do with my work, I suppose. I look into the distance for those I have lost, so that I see them everywhere. Even here in Dému, where Lucien Segura existed" (D 143). It would be a huge coincidence if a character who is scarred by and distanced from her past accidentally turned up on a street that fittingly reflected their behaviour with the additional benefit of describing their style of work, especially since many parts of her narrative shed similar moments of doubt on her reliability as a narrator.

Considering Ondaatje's careful structuring of his novels and the significance of even the smallest details, I cannot believe that this is done without some deliberation. Such a 'coincidence' does indeed fit perfectly with Ondaatje's tendency to dilute boundaries since it effectively blurs the line between fact and fiction and leaves the reader uncertain of what can be trusted anymore. After all, the address on Divisadero Street is one of the few pieces of information that is actually available about Anna. ${ }^{44}$ If she does not really live there and it is merely a metaphoric description of the way she leads her life, Divisadero Street could also describe her state of mind while being in France and reflecting on her past which is territorially and geographically distanced in California. The novel's structure certainly supports such a reading as the following chapter will detail.

44 She even changed her name but does not tell us her new one as the framing passages before the first chapter indicates. 


\subsubsection{Everything Is Collage}

Even though Divisadero's title suggests a division, the novel's halves are nevertheless intricately connected through a string of recurring motifs. Parts of one storyline constantly turn up in one another: the blue table of Anna's boyfriend reappears in Lucien's house in France ( $D$ 30; 70; 93; 239); the flags Anna gives to Coop are suddenly present when he is almost beaten to death by the poker players as well as when he and Claire meet his former friends ( $D$ 132; 161); Stendhal's The Red and the Black is used as a chapter heading for Coop's story in Tahoe (D 39), additionally mentioned in the narrative strand that follows Anna's life in France (D 77), while Claire and Coop accidentally meet again after years of not having seen one another in a club called "The Stendhal" ( $D$ 106). There are many more of these examples, which finely sew together the different parts of Divisadero. The lives of Anna, Claire and Coop are thus not as absent from the second half of the book as it seemed at first.

This leaves the question of why this is done. In any case, it reflects the motto that "everything is collage" which is twice mentioned by Anna during the narration of her youth (D 16-17). It also evokes her similar quotation that "everything is biographical" (D 16) and her occupation with "piec[ing] together the landscapes [Segura] had written about" (D 144). With all this emphasis on piecing together and collages, mixed with the inevitable reference to French literature - Stendhal and the notion that everything is also biographical it is not far-fetched to conclude that maybe Anna is the one who does the piecing.

Further close parallels between the events in Anna's youth and the life of Segura strengthen this perception additionally. Segura is characterized as someone who "lived mostly an imaginary life" and preferred the company of fictional characters in troubled times ( $D$ 173). At one point he finds a journal by his wife that leads to his realization that he did not know her at all ( $D$ 223) just like Anna begins to understand that she did not know her sister at all after having read her diary (D 138-9). Additionally, a number of scholarly remarks in the parts that are not narrated in first person by Anna could indicate that she, being a scholar, narrated these parts as well, including the life of Segura. What narrator would otherwise mention that they "have recently been reading, in a monograph a haunting thing" (D 142) or reflect on "Sanskrit poetics" (D 152)?

Together with her conviction that "[ $\mathrm{t}]$ he third-person voice protects us" and that "sometimes we enter art to hide within it" ( $D$ 142), the probability that all storylines are narrated by Anna is further strengthened. Her admission that "we live with those retrievals from childhood [...] making up a single monologue" ( $D$ 136) finally seems to sum up and explain the strange structure of this novel. Anna would hence be seen as the novel's narrator who invents or at least strongly influ- 
ences the other storylines. ${ }^{45}$ Having lost her home and her family she tries to imagine them in the space of the novel in which she is constantly linked to and connected with them across geographical and temporal distances. The novel can then be seen as her imagined world. However, even this conclusion is by no means certain since, after all, Anna also in a striking passage reflects upon a story of how one twin can absorb another in the womb: "And perhaps this is the story of twinship. I have smuggled myself away from who I was, and what I was. But am I the living twin in the story of our family? Or is it Claire? Who is the stilled one?" (D 141).

The only thing that can be said with certainty about Divisadero is that it is filled with uncertainty. Meaning is always open and infinite as everything in the novel seems interconnected. The longer one tries to separate the different parts, the closer they stick together. In the space of the novel all boundaries are blurred and everything is part of the other. This might make it a "stubbornly eclectic" book, to quote Maslin again, but it also makes it a rather fitting illustration of the transnational condition as 'Anna' certainly seems to simultaneously take part in all the different parts of the book.

\section{Conclusion}

Michael Ondaatje's fiction and transnational conceptions of space appear to suit one another rather well when it comes to the depiction of characters' identities. Ondaatje's description of the spaces of identity in which different nations and cultures are joined in boundary-transgressing unity precisely echoes transnationalism's perspective on the simultaneous experience of here and there of transnational lives.

Nevertheless, Ondaatje's works do not only accentuate the positive experiences of transnational identities but also address their difficulties, such as the problem of different belief systems - for example in Anil's Ghost - which suppress the successful formation of transnational identities. Touching upon a similar concern, the rejection of migrants in the country of immigration is a topic in The English Patient. The texts can therefore not be seen as a simple celebration of multicultural or postnational ways of life, but reflect the challenges many contemporary migrants are faced with in a nuanced way: all stories are marked by a strong desire to unite spaces and transcend boundaries, no matter how successful they are in achieving it and thus seem to echo contemporary forms of life and identities

45 Since already near the beginning some form of omniscience and all-encompassing presence is associated with, or better self-attributed to Anna ( $D$ 27), it would not be surprising to take up this perspective again while speculating about the lives of those she lost. She certainly thinks she "can imagine most things about Claire accurately" (D 139) even though she has not seen her in almost 20 years. 
which are not bound by the borders of nation-states. The focus on transnationalism is even present in Ondaatje's latest novel, which is hardly concerned with migration at all: in Divisadero the same concerns are addressed, even though the novel appeared completely opposed to transnational theories at first.

As my analysis of the texts has shown, theories on the phenomenon of transnational migration describe the nature of identities in Ondaatje's fiction much more fittingly than the usual postcolonial concepts of liminality and hybridity. Reading these texts from such a perspective brings out the finer points and subtleties that all his fictional works contain. The clear-cut categories usually applied to Ondaatje's writing cannot (un)cover these aspects and are not able to do the texts justice because they do not pay attention to the complex and detailed way the issue of transnational identities is dealt with in them. Hardly surprising, these ordinarily used categories are at times even downright rejected in the texts, such as in In the Skin of a Lion. It appears that Ondaatje's fiction strives to go beyond ordinary categories. Given Ondaatje's long-standing interest in the topic, starting with Running in the Family in 1982 up to Divisadero in 2007, the novels undoubtedly do not address a quickly passing trend in the perspective on migration but rather seem to reflect a different form of migration. I therefore conclude that Ondattje's fiction can be described as a different form of migrant writing altogether. It would now be interesting to compare other migrant literature to it to see if this is the beginning of a new development in migrant writing or just a singular occurrence. 


\section{Bibliography}

Primary Literature

Achebe, Chinua. Things Fall Apart. New York: Anchor, 1994.

Desai, Kiran. The Inheritance of Loss. London: Penguin, 2006.

Donne, John. "Meditation 17." The Norton Anthology of English Literature. 8th ed. Vol. 1. Ed. Stephen Greenblatt and M.H. Abrams. New York: Norton, 2006. 1305-1306.

Forster, E.M. A Passage to India. London: Penguin, 1979.

Kunzru, Hari. Transmission. New York: Plume, 2005.

Ondaatje, Michael. Anil's Ghost. London: Picador, 2000.

- Divisadero. New York: Knopf, 2007.

- The English Patient. London: Bloomsbury, 1992.

- Running in the Family. New York: Vintage, 1993.

- In the Skin of a Lion. New York: Vintage, 1997.

Roy, Arundhati. The God of Small Things. London: Flamingo, 1998.

Secondary Literature

“About Migration." International Organization for Migration. 4 June 2009. http://www.iom.int/jahia/Jahia/lang/en/pid/3.

Anderson, Benedict. Imagined Communities. Rev. ed. London: Verso, 2006.

Appadurai, Arjun. Modernity at Large: Cultural Dimensions of Globalization. $7^{\text {th }}$ ed. Public Worlds 1. Minneapolis: U of Minnesota P, 2005.

Ashcroft, Bill, Gareth Griffiths and Helen Tiffin. The Empire Writes Back: Theory and Practice in Post-colonial Literatures. $2^{\text {nd }}$ ed. London: Routledge, 2003.

- "Exile." Key Concepts in Post-Colonial Studies. London: Routledge, 1998. 92-94.

- "Liminality." Key Concepts in Post-Colonial Studies. London: Routledge, 1998. 13031.

Barry, Peter. Beginning Theory: An Introduction to Literary and Cultural Theory. $2^{\text {nd }}$ ed. Manchester: MUP, 2002.

Beck, Ulrich. " Living Your Own Life in a Runaway World: Individualisation, Globalisation and Politics." Globalization: Critical Concepts in Sociology. Vol. IV Culture and Identity. Ed. Roland Robertson and Kathleen E. White. London: Routledge, 2003. 272-80.

- Was ist Globalisierung? Irrtümer des Globalismus - Antworten auf Globalisierung. $6^{\text {th }}$ ed. Frankfurt a.M.: Suhrkamp, 1999. 
Bhabha, Homi K. The Location of Culture. Routledge Classics. London: Routledge, 2004.

- "The Third Space." Interview with Jonathan Rutherford. Identity: Community, Culture, Difference. Ed. Jonathan Rutherford. London: Lawrence and Wishart, 1990. 207-21.

Boehmer, Elleke. Colonial and Postcolonial Literature: Migrant Metaphors. $2^{\text {nd }}$ ed. Oxford: OUP, 2005.

Bölling, Gordon. History in the Making: Metafiktion im neueren anglokanadischen historischen Roman. Heidelberg: Winter, 2006.

Bowers, Maggie Ann. "Global, National and Local Identities: The Transformative Effects of Migrant Literatures." International Migration and Security: Opportunities and Challenges. Ed. Elspeth Guild and Joanne van Selm. London: Routledge, 2005. 147-56.

Brennan, Timothy. "The National Longing for Form." Nation and Narration. Ed. Homi K. Bhabha. London: Routledge, 1990. 44-70.

Brubaker, Rogers and Frederick Cooper. "Beyond 'Identity." Theory and Society 29.1 (2000): 1-47.

Burcar, Lilijana. "Re-Mappig Nation, Body and Gender in Michael Ondaatje's The English Patient." The Flesh Made Text Made Flesh: Cultural and Theoretical Returns to the Body. Ed. Zoe Detsi-Diamanti, Katerina Kitsi-Mitakou and Effie Yiannopoulou. New York: Peter Lang, 2007. 99-110.

Burton, Antoinette. "Archive of Bones: Anil's Ghost and the Ends of History." The Journal of Commonwealth Literature 38 (2003): 39-56.

Çağlar, Ayse S. "Constraining Metaphors and the Transnationalisation of Spaces in Berlin." Journal of Ethnic and Migration Studies 27.4 (2001): 601-13.

Castles, Stephen and Mark J. Miller. The Age of Migration: International Population Movements in the Modern World. New York: Guilford Press, 1993.

Chambers, Iain. Migrancy, Culture, Identity. London: Routledge, 1994.

Chan, Joseph M. and Eric Ma. "Transculturating Modernity: A Reinterpretation of Cultural Globalization." In Search of Boundaries: Communication, Nation-States and Cultural Identities. Ed. Joseph M. Chan and Bryce T. McIntyre. Advances in Communication and Culture. Westport, CT: Ablex, 2002. 3-18.

Clifford, James. "Diasporas.” Cultural Anthropology 9.3 (1994): 302-38.

Cook, Rufus. "Being and Representation in Michael Ondaatje's The English Patient." ARIEL 30.4 (1999): 35-49.

Cook, Victoria. "Exploring Transnational Identities in Ondaatje's Anil's Ghost." Comparative Cultural Studies and Michael Ondaatje's Writing. Ed. Steven Tötösy de Zepetnek. West Lafayette: Purdue UP, 2005. 6-15. 
Criglington, Meredith. "The City as Site of Counter-Memory in Anne Michael's Fugitive Pieces and Michael Ondaatje's In the Skin of a Lion." Essays on Canadian Writing 81 (2004): 129-51.

Delbaere, Jeanne. "'Only Re-Connect': Temporary Pacts in Michael Ondaatje's The English Patient." The Contact and the Culmination. Ed. Marc Delrez and Bénédicte Ledent. Liège: Liège Language and Literature: 1997. 45-56.

Derrickson, Teresa. 'Will the 'Un-truth' Set You Free? A Critical Look at Global Human Rights Discourse in Michael Ondaatje's Anil's Ghost.” Literature Interpretation Theory 15 (2004): 131-52.

Duffy, Dennis. "A Wrench in Time: A Sub-Sub-Librarian Looks beneath the Skin of a Lion." Essays on Canadian Writing 53 (1994): 125-40.

During, Simon. "Literature - Nationalism's Other? The Case for Revision." Nation and Narration. Ed. Homi K. Bhabha. London: Routledge, 1990. 138-53.

Easthope, Anthony. "Bhabha, Hybridity and Identity." Textual Practice 12.2 (1998): 341-48.

Farrier, David. "Gesturing Towards the Local: Intimate Histories in Anil's Ghost." Journal of Postcolonial Writing 41:1 (2005): 83-93.

Getachew, Mahlete-Tsigé. "Marginalia: Black Literature and the Problem of Recognition." Write Black, Write British: From Postcolonial to Black British Literature. Herford: Hansib, 2005. 323-45.

Glick Schiller, Nina, Linda Basch and Cristina Blanc-Szanton. "Transnationalism: A New Analytic Framework for Understanding Migration." Towards a Transnational Perspective on Migration: Race, Class, Ethnicity, and Nationalism Reconsidered. Ed. Nina Glick Schiller, Linda Basch and Cristina Blanc-Szanton. Annals of the New York Academy of Sciences 645. New York: The New York Academy of Sciences, 1992. 1-24.

Glick Schiller, Nina, Linda Basch and Christina Szanton Blanc. "From Immigrant to Transmigrant: Theorizing Transnational Migration." Migration and Transnational Social Spaces. Ed. Ludger Pries. Aldershot: Ashgate, 1999. 73-105.

"Global Estimates." International Organization for Migration. 4 June 2009. <http://www.iom.int/jahia/Jahia/about-migration/facts-and-figures/globalestimates-and-trends $>$.

Glover, Brenda. "'Unanchored to the World': Displacement and Alienation in Anil's Ghost and the Prose of Michael Ondaatje." CRNLE Journal (2000): 75-80.

Godard, Barbara. "Notes from the Cultural Field: Canadian Literature from Identity to Hybridity." Essays on Canadian Writing 72 (2000): 209-47.

Goldman, Marlene. "War and the Game of Representation in Michael Ondaatje's The English Patient." Re-Constructing the Fragments of Michael Ondaatje's Works / La diversité d'construite et reconstruite de l'auvre de Michael Ondaatje. Ed. Jean-Michel Lacroix. Paris: Presses de la Sorbonne Nouvelle, 1999. 181-93. 
Gorjup, Branko. "Michael Ondaatje's Reinvention of Social and Cultural Myths: In the Skin of a Lion." Acta Neophilologica 22 (1989): 89-95.

Griem, Julika. "Hybridität." Metəler Lexikon Literatur- und Kulturtheorie: Ansätz̨e, Personen, Grundbegriffe. Ed. Ansgar Nünning. Stuttgart: Metzler, 2004. $269-70$.

Hall, John A. "Transatlantic Images of Belonging." The Postnational Self: Belonging and Identity. Ed. Ulf Hedetoft and Mette Hjort. Public Worlds 10. Minneapolis: U of Minnesota P, 2002. 53-65.

Hall, Stuart. "Cultural Identity and Diaspora." Identity: Community, Culture, Difference. Ed. Jonathan Rutherford. London: Lawrence and Wishart, 1990. 222-37.

Hannerz, Ulf. "Where We Are and Who We Want to Be." The Postnational Self: Belonging and Identity. Ed. Ulf Hedetoft and Mette Hjort. Public Worlds 10. Minneapolis: U of Minnesota P, 2002. 217-32.

Harzig, Christiane and Dirk Hoerder. "Transnationalism and the Age of Mass Migration, 1880s to 1920s." Transnational Identities and Practices in Canada. Ed. Vic Satzewich and Lloyd Wong. Vancouver: UBC Press, 2006. 35-51.

Heble, Ajay. "Putting Together Another Family: In the Skin of a Lion, Affiliation, and the Writing of Canadian (Hi)stories." Essays on Canadian Writing 56.1 (1995): 236-54.

- "'Rumours of Topography': The Cultural Politics of Michael Ondaatje's Running in the Family." Essays on Canadian Writing 53 (1994): 186-203.

Hedetoft, Ulf and Mette Hjort. Introduction. The Postnational Self: Belonging and Identity. Ed. Ulf Hedetoft and Mette Hjort. Public Worlds 10. Minneapolis: U of Minnesota P, 2002. vii-xxxii.

Hollifield, James. "The Emerging Migration State." Rethinking Migration: New Theoretical and Emperical Perspectives. Ed. Alejandro Portes and Josh DeWind. New York and Oxford: Berghahn Books, 2007. 62-89.

Horatschek, Annegreth. "Kollektive Identität." Metzler Lexikon Literatur- und Kulturtheorie: Ansätz̨e, Personen, Grundbegriffe. Ed. Ansgar Nünning. Stuttgart: Metzler, 2004. 276-77.

Huddart, David. Homi K. Bhabha. Routledge Critical Thinkers. Abingdon: Routledge, 2006.

Huggan, Graham. "Exoticism and Ethnicity in Michael Ondaatje's Running in the Family." Writing Ethnicity: Cross-Cultural Consciousness in Canadian and Québécois Literature. Ed. Winfried Siemerling. Toronto: ECW, 1996. 116-27.

Ibarrola-Armendariz, Aitor. "Boundary Erasing: Postnational Characterization in Michael Ondaatje's The English Patient." Tricks With a Glass: Writing Ethnicity in Canada. Ed. Rocío G. Davis and Rosalía Baena. Cross/Cultures 46. Amsterdam: 2000. 37-57. 
Ingelbien, Raphaël. "A Novelist's Caravaggism: Michael Ondaatje’s In the Skin of a Lion." The Guises of Canadian Diversity: New European perspectives = Les masques de la diversité canadienne. Ed. Jaumain Serge and Marc Manfort. Cross/Cultures 19. Amsterdam: Rodopi, 1995. 27-37.

Innes, C.L. The Cambridge Introduction to Postcolonial Literatures in English. Cambridge: CUP, 2007.

Iyer, Pico. "A New Kind of Mongrel Fiction." Rev. of Divisadero, by Michael Ondaatje. The New York Review of Books 54.11 (2007).

Jackson, Peter, Philip Crang and Claire Dwyer. "Introduction: The Spaces of Transnationality." Transnational Spaces. Ed. Peter Jackson, Philip Crang and Claire Dwyer. Transnationalism 6. London: Routledge, 2004. 1-23.

Kamboureli, Smaro. "The Alphabet of the Self: Generic and Other Slippages in Michael Ondaatje's Running in the Family." Reflections: Autobiography and Canadian Literature. Ed. K.P. Stich. Ottawa: U of Ottawa P, 1988. 79-91.

- "The Culture of Celebrity and National Pedagogy." Home-Work: Postcolonialism, Pedagogy \& Canadian Literature. Ed. Cynthia Sugars. Reappraisals: Canadian Writers 28. Ottawa: U of Ottawa P, 2004. 35-55.

Kastoryano, Riva. "Citizenship and Belonging: Beyond Blood and Soil." The Postnational Self: Belonging and Identity. Ed. Ulf Hedetoft and Mette Hjort. Public Worlds 10. Minneapolis: U of Minnesota P, 2002. 120-36.

Kella, Elizabeth. Beloved Communities: Solidarity and Difference in Fiction by Michael Ondaatje, Toni Morrison, and Joy Kogawa. Studia Anglistica Upsaliensia 110. Uppsala: Uppsala University Library, 2000.

Kemp, Mark A. R. "Italy and the Ruins of Western Civilization: Michael Ondaatje's The English Patient.” NEML A Italian Studies 21 (1997): 131-55.

Leon, Carol. "Diaspora Space: The Practice of Biography in Michael Ondaatje's Running in the Family." Sri Lanka Journal of the Humanities 27-28.1-2 (2001-02): 24-37.

Levitt, Peggy and Nina Glick Schiller. "Conceptualizing Simultaneity: A Transnational Social Field Perspective on Society." Rethinking Migration: New Theoretical and Emperical Perspectives. Ed. Alejandro Portes and Josh DeWind. New York: Berghahn Books, 2007. 181-218.

Levitt, Peggy. The Transnational Villagers. Berkeley: UCP, 2001.

Lisle, Debbie. The Global Politics of Contemporary Travel Writing. Cambridge, CUP: 2006.

Löfgren, Orvar. "The Nationalization of Anxiety: A History of Border Crossings." The Postnational Self: Belonging and Identity. Ed. Ulf Hedetoft and Mette Hjort. Public Worlds 10. Minneapolis: U of Minnesota P, 2002. 250-74.

Loomba, Ania. Colonialism/Postcolonialism. 2nd ed. London: Routledge, 2005. 
Lowry, Glen. "The Representation of 'Race' in Ondaatje's In the Skin of a Lion." Comparative Cultural Studies and Michael Ondaatje's Writing. Ed. Steven Tötösy de Zepetnek. West Lafayette: Purdue UP, 2005. 62-72.

Maslin, Janet. "Strands May Be Delicate, but They're All Connected." Rev. of Divisadero, by Michael Ondaatje. The New York Times 11 June 2007. 8 April 2008. http://www.nytimes.com/2007/06/11/books/11masl.html?scp=4\& $\mathrm{sq}=$ divisadero $\% 20$ ondaatje\&st $=\mathrm{cse}>$

Mason, Jody. "'The Animal out of the Desert': The Nomadic Metaphysics of Michael Ondaatje's In the Skin of a Lion." Studies in Canadian Literature 31.2 (2006): 66-87.

McLeod, John. Beginning Postcolonialism. Manchester: MUP, 2000.

Mukherjee, Arun P. "The Poetry of Michael Ondaatje and Cyril Dabydeen: Two Responses to Otherness." The Journal of Commonwealth Literature 20.1 (1985): 49-67.

Overbye, Karen. "Remembering the Body: Constructing the Self as Hero in In the Skin of a Lion." Studies in Canadian Literature 17.2 (1992): 1-13.

Papayanis, Marylin Adler. Writing in the Margins: The Ethics of Expatriation from Lawrence to Ondaatje. Nashville: Vanderbilt UP, 2005.

Parker, Peter. Rev. of Divisadero, by Michael Ondaatje. Times Online 23 September 2007. 8 April $2008<$ http://entertainment.timesonline.co.uk/tol/arts_and_ entertainment/books/fiction/article2500258.ece>

Perosa, Sergio. "Michael Ondaatje's In the Skin of a Lion and the Building of Cities." Imagination and the Creative Impulse in the New Literatures in English. Ed. M.-T. Bindella and G.V. Davis. Cross/Cultures 9. Amsterdam: Rodopi, 1993. 18189.

Pesch, Josef. "Mediation, Memory and a Search for the Father: Michael Ondaatje's Running in the Family." Zeitschrift für Anglistik und Amerikanistik: A Quarterly of Language, Literature and Culture 45.1 (1997): 556-71.

Portes, Alejandro and Josh DeWind. "A Cross-Atlantic Dialogue: The Progress of Research and Theory in the Study of International Migration." Rethinking $M i$ gration: New Theoretical and Emperical Perspectives. Ed. Alejandro Portes and Josh DeWind. New York: Berghahn Books, 2007. 3-26.

Pries, Ludger. "New Migration in Transnational Spaces." Migration and Transnational Social Spaces. Ed. Ludger Pries. Aldershot: Ashgate, 1999. 1-35.

Ray, Sangeeta. "Memory, Identity, Patriarchy: Projecting a Past in the Memoirs of Sara Suleri and Michael Ondaatje.” Modern Fiction Studies 39.1 (1993): 37-58.

Renan, Ernest. "What is a Nation?" Nation and Narration. Ed. Homi K. Bhabha. London: Routledge, 1990. 8-22.

Rushdie, Salman. Imaginary Homelands: Essays and Criticism 1981-91. London: Granta Books, 1992. 
Said, Edward W. Culture and Imperialism. New York: Vintage, 1993.

Satzewich, Vic and Lloyd Wong. "Conclusion: Directions for Future Research." Transnational Identities and Practices in Canada. Ed. Vic Satzewich and Lloyd Wong. Vancouver: UBC Press, 2006. 296-98.

Saul, Joanna. Writing the Roaming Subject: The Biotext in Canadian Literature. Toronto: U of Toronto P, 2006.

Schiffauer, Werner, Gerd Baumann, Riva Kastoryano and Steven Vertovec. Civil Enculturation: Nation-State, Schools and Ethnic Difference in Four European Countries. New York: Berghahn, 2004.

Schumacher, Rod. "Patrick's Quest: Narration and Subjectivity in Michael Ondaatje's In the Skin of a Lion." Studies in Canadian Literature 21.2 (1996): 1-21.

Shin, Andrew. "The English Patient's Desert Dream." Lit: Literature Interpretation Theory 18.3 (2007): 213-35.

Siemerling, Winfried. "Oral History and the Writing of the Other in Ondaatje's In the Skin of a Lion." Comparative Cultural Studies and Michael Ondaatje's Writing. Ed. Steven Tötösy de Zepetnek. West Lafayette: Purdue UP, 2005. 92-103.

Smith, Robert. "Reflections on Migration, the State and the Construction, Durability and Newness of Transnational Life." Migration and Transnational Social Spaces. Ed. Ludger Pries. Canadiana 1. Aldershot: Ashgate, 1999. 187-219.

Smyrl, Shannon. 'The Nation as 'International Bastard': Ethnicity and Language in Michael Ondaatje's The English Patient.” SCL/ÉLC 28.2 (2003): 9-38.

Snelling, Sonia. "A Human Pyramid': An (Un)Balancing Act of Ancestry and History in Joy Kogawa's Obasan and Michael Ondaatje's Running in the Family." Journal of Commonwealth Literature 32.1 (1997): 21-33.

Spearey, Susan. "Mapping and Masking: The Migrant Experience in Michael Ondaatje's In the Skin of a Lion." The Journal of Commonwealth Literature 29.2 (1994): 45-60.

Stolar, Batia Boe. "Building and Living the Immigrant City: Michael Ondaatje's and Austin Clarke's Toronto." Downtown Canada: Writing Canadian Cities. Ed. Justin D. Edwards and Douglas Ivison. Toronto: U of Toronto P, 2005. 12241.

Turcotte, Gerry. "Venturing into Undiscoverable Countries: Reading Ondaatje, Malouf, Atwood \& Jia in an Asia-Pacific Context." Australian-Canadian Studies 15.2-16.1 (1997-98): 65-72.

United Nations. "Estimated Number of International Migrants at Mid-Year." United Nations. 2006. 12 February 2009. < http://esa.un.org/migration/index. asp?panel $=1>$. Path: Estimated number of international migrants at mid-year (both sexes); World. 
- "International Migrants as a Percentage of the Population." United Nations. 2006. 12 February 2009. <http://esa.un.org/migration/index.asp?panel=1>. Path: International Migrants as a percentage of the population: World.

Vauthier, Simone. "A Story of Silence and Voices: Michael Ondaatje's In the Skin of a Lion." Multiple Voices: Recent Canadian Fiction: Proceedings of the $4^{\text {th }}$ International Symposium of Brussels Centre for Canadian Studies 29 November - 1 December 1989. Ed. Jeanne Delbaere. Sydney: Dangaroo P, 1990. 69-90.

Vertovec, Steven. "Migrant Transnationalism and Modes of Transformation." Rethinking Migration: New Theoretical and Emperical Perspectives. Ed. Alejandro Portes and Josh DeWind. New York: Berghahn Books, 2007. 149-79.

- "Transnationalism and Identity." Journal of Ethnic and Migration Studies 27.4 (2001): 573-82.

Wayland, Sarah V. "The Politics of Transnationalism: Comparative Perspectives." Transnational Identities and Practices in Canada. Ed. Vic Satzewich and Lloyd Wong. Vancouver: UBC Press, 2006. 18-34.

Werth, Wolfgang. "Immigration and Acculturation in Michael Ondaatje's In the Skin of a Lion." Wandering Selves: Essays on Migration and Multiculturalism. Ed. Michael Porsche and Christian Berkemeier. Arbeiten zur Amerikanistik 29. Essen: Die Blaue Eule, 2001. 125-33.

White, Paul. "Geography, Literature and Migration." Writing across Worlds: Literature and Migration. Ed. Russel King, John Connel and Paul White. London: Routledge, 1995. 1-19.

Wong, Lloyd and Vic Satzewich. "Introduction: The Meaning and Significance of Transnationalism." Transnational Identities and Practices in Canada. Ed. Vic Satzewich and Lloyd Wong. Vancouver: UBC Press, 2006. 1-15.

Wong, Lloyd L. "Home away from Home? Transnationalism and the Canadian Citizenship Regime." Communities across Borders: New Immigrants and Transnational Cultures. Ed. Paul Kennedy and Victor Roudometof. Transnationalism 5. London: Routledge, 2002. 169-81.

Woznialis, Danuta. "Identity as an Open-Ended Process: Michael Ondaatje's Works." Dabai ir Dienos 32 (2002): 267-90.

Yeoh, Brenda S.A., Karen P.Y. Lai, Michael W. Charney and Tong Chee Kiong. "Approaching Transnationalisms." Approaching Transnationalisms: Studies on Transnational Societies, Multicultural Contacts, and Imaginings of Home. Ed. Brenda S. A. Yeoh, Michael W. Charney and Tong Chee Kiong. Boston: Kluwer, 2003. $1-12$.

Younis, Raymond Aaron. "Nationhood and Decolonization in The English Patient." Canadian Journal of Film Studies / Revue canadienne d'études cinématographiques 6.1 (1997): 2-9

- "Race, Representation and Nationhood." Australian-Canadian Studies 15.2-16.1 (1997-98): 43-63. 